ARTICLE

\title{
Enhanced dispersion stability of gold nanoparticles by the physisorption of cyclic poly(ethylene glycol)
}

Yubo Wang (1) 1, Jose Enrico Q. Quinsaat (10 2, Tomoko Ono², Masatoshi Maeki (1) 2, Manabu Tokeshi ${ }^{2}$,

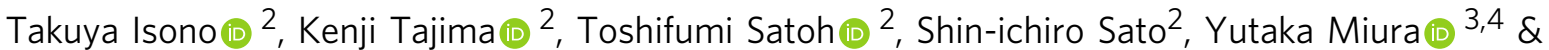
Takuya Yamamoto (iD) 2 的

Nano-sized metal particles are attracting much interest in industrial and biomedical applications due to the recent progress and development of nanotechnology, and the surfacemodifications by appropriate polymers are key techniques to stably express their characteristics. Herein, we applied cyclic poly(ethylene glycol) (c-PEG), having no chemical inhomogeneity, to provide a polymer topology-dependent stabilization for the surfacemodification of gold nanoparticles (AuNPs) through physisorption. By simply mixing c-PEG, but not linear counterparts, enables AuNPs to maintain dispersibility through freezing, lyophilization, or heating. Surprisingly, c-PEG endowed AuNPs with even better dispersion stability than thiolated PEG (HS-PEG-OMe). The stronger affinity of c-PEG was confirmed by DLS, $\zeta$-potential, and FT-IR. Furthermore, the c-PEG system exhibited prolonged blood circulation and enhanced tumor accumulation in mice. Our data suggests that c-PEG induces physisorption on AuNPs, supplying sufficient stability toward bio-medical applications, and would be an alternative approach to the gold-sulfur chemisorption.

\footnotetext{
${ }^{1}$ Graduate School of Chemical Sciences and Engineering, Hokkaido University, Sapporo, Hokkaido 060-8628, Japan. ${ }^{2}$ Division of Applied Chemistry, Faculty of Engineering, Hokkaido University, Sapporo, Hokkaido 060-8628, Japan. ${ }^{3}$ Department of Bioengineering, Graduate School of Engineering, The University of Tokyo, 7-3-1 Hongo, Bunkyo-ku, Tokyo 113-8656, Japan. ${ }^{4}$ Laboratory for Chemistry and Life Science, Institute of Innovative Research, Tokyo Institute of

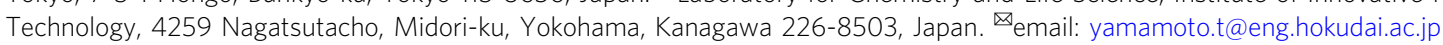


etal nanoparticles represent a widely interesting group of materials due to their unique properties which differ from their respective bulk state. Presently, metal nanoparticles are used in a wide range of applications which include optics ${ }^{1}$, sensors ${ }^{2}$, biomedicine ${ }^{3}$, electronics ${ }^{4}$, and catalysis $^{5}$. Metal nanoparticles such as gold, silver, and copper nanoparticles exhibit surface plasmon resonances (SPR) as a result of their interaction with light which manifests itself in the different colors of the corresponding colloidal solutions depending on the particle size and shape ${ }^{6}$. However, metal nanoparticles are not a stable material and easily aggregate to lose SPR absorption and thus need to be kept as a solution at low temperature. Yet, freezing the solution also causes aggregation and cannot be redispersed. Moreover, the dispersion stability in solution is also affected by various parameters such as salt concentration ${ }^{7}$, temperature ${ }^{8}$ or $\mathrm{pH}^{9}$, all of which eventually lead to particle dissolution or aggregation. Hence, metal nanoparticles are often either kept in a citrate solution or reacted with thiolated molecules to gain dispersion stability ${ }^{10}$.

Over the past decades, there have been numerous reports on the dispersion stabilization of gold nanoparticles (AuNPs), the most representative metal nanoparticles, using poly(ethylene glycol) (PEG) as a stabilizer, namely PEGylation ${ }^{11}$. PEG is a neutral water-soluble polymer with a flexible backbone and is well-known for its ability to bind to water through hydrogen bonding ${ }^{12}$. Additionally, PEG is biocompatible and can protect gold surfaces from aggregation in vitro and in vivo as well as from detection by the immune system ${ }^{13}$. When biological applications are considered, the stability against salts in physiological conditions is an indispensable property. The increase in the ionic strength through the addition of a salt or electrolyte reportedly leads to aggregation ${ }^{13}$. Therefore, proper surface-modification is essential to avoid aggregation. However, PEGylation, as well as other functionalizations, of AuNPs has been almost limited to chemisorption by the gold-sulfur reactions, and thus, it is important to establish a new PEGylation methodology for the development of nanoparticle sciences.

Although the stabilization of nanoparticles by a polymer has extensively been explored over the years by tuning various parameters such as molecular weight ${ }^{14}$ or composition ${ }^{15}$, very little attention has been paid on the potential contribution of the polymer topology. Over the last decade, numerous articles on the cyclization of various polymers through different routes have been reported which yielded polymers with different topologies ${ }^{16,17}$. The cyclized polymers exhibited distinct properties compared to their linear counterparts of the same molecular weight such as higher density, higher glass transition temperature, smaller hydrodynamic volume, and lower viscosity ${ }^{18,19}$. In particular, the dispersion stability exhibited by the cyclic polymers is an interesting feature which could be exploited for the stability of nanoparticles. Thus, we reported that micelles composed of cyclized PEG-containing amphiphilic block copolymers feature a higher tolerance towards temperature and salinity compared to their linear counterparts in an aqueous solution, which was proven by turbidity tests and dynamic light scattering ${ }^{20-22}$. Moreover, cyclic polyoxazoline chemisorbed to a titanium oxide surface, $\mathrm{Fe}_{3} \mathrm{O}_{4}$ nanoparticles, or a degraded cartilage formed a denser layer than the linear counterpart ${ }^{23-25}$.

In this work, the use of PEG as a polymeric stabilizer of AuNPs, where the effects of the polymer topology (linear vs. cyclic) as well as the end groups (-OH vs. -OMe vs. $-\mathrm{SH}$ ) against freezing, lyophilization, heating, and a physiological condition, is investigated with the above observations in mind (Supplementary Fig. 1). In consequence, we find that $c$-PEG endows AuNPs with enhanced dispersion stability.

\section{Results}

Synthesis of $c$-PEG. PEG was cyclized via etherification, thus forming cyclic PEG (c-PEG) without inhomogeneity in the chemical structure, by using the modified tosylation method according to previous reports (Fig. 1a) ${ }^{26,27}$. The molecular weight was $1,3,5$, and $10 \mathrm{kDa}$ (namely, $c-\mathrm{PEG}_{1 \mathrm{k}}, c-\mathrm{PEG}_{3 \mathrm{k}}, c-\mathrm{PEG}_{5 \mathrm{k}}$, and $c$ - $\mathrm{PEG}_{10 \mathrm{k}}$, respectively, shown in Table 1). The expected diameter of $c-\mathrm{PEG}_{1 \mathrm{k}}, c-\mathrm{PEG}_{3 \mathrm{k}}, c-\mathrm{PEG}_{5 \mathrm{k}}$, and $c-\mathrm{PEG}_{10 \mathrm{k}}$ was $2.2,7.4,14$, and $28 \mathrm{~nm}$, respectively, when they form an ideal right circular conformation. The shift in the size exclusion chromatography (SEC) traces confirms the change in the polymer topology as a result of the decrease in the hydrodynamic volume upon cyclization (Fig. 1d and Supplementary Fig. 2). For example, peak top molecular weight $\left(M_{\mathrm{p}, \mathrm{SEC}}\right)$ of $\mathrm{PEG}_{3 \mathrm{k}}$ decreased from 3100 to 2090 upon cyclization. The small values of polydispersity index $\left(M_{\mathrm{w}} /\right.$ $M_{\mathrm{n}}$ ), except for $\mathrm{PEG}_{1 \mathrm{k}}$, allowed for clear discussion on the molecular-weight dependence. Furthermore, matrix-assisted laser desorption ionization time-of-flight (MALDI-TOF) mass spectrometry and NMR also featured the difference between the linear and cyclic polymer species. For instance, the MALDI-TOF mass spectrum of $\mathrm{HO}-\mathrm{PEG}_{3 \mathrm{k}}-\mathrm{OH}$ showed a peak at $\mathrm{m} / z=2062.10$ $\left(\mathrm{DP}_{\mathrm{n}}=44, \mathrm{Ag}^{+}\right.$adduct $)$, whereas the corresponding peak from $c$ PEG was at $m / z=2044.02$; the value in the isotope distribution shifted by a mass unit of 18 due to the net elimination of a water molecule upon cyclization (Fig. 1e and Supplementary Fig. 3). The experimental $\mathrm{m} / z$ values for the monoisotopic mass of $c$ $\mathrm{PEG}_{3 \mathrm{k}}$ well matched to the calculated values for its molecular weight distribution range (Supplementary Table 1). In the ${ }^{13} \mathrm{C}$ NMR spectra, the peak at $61.8 \mathrm{ppm}$ and $72.5 \mathrm{ppm}$ observed for the carbon atoms adjacent to the terminal hydroxy groups in HO-PEG-OH vanished upon cyclization, thus confirming the effective elimination of the end groups (Fig. $1 \mathrm{~b}$ and Supplementary Fig. 4). ${ }^{1} \mathrm{H}$ NMR also showed the high symmetry of $c$-PEG by the single peak of the methylene protons (Fig. 1c and Supplementary Fig. 5). MeO-PEG-OMe was synthesized from HOPEG-OH with iodomethane under an alkaline condition ${ }^{26}$. Essentially, no absorption from purified PEG was confirmed by UV-Vis spectroscopy, allowing for the clear observation of the SPR absorption of AuNPs. The comparison of highly pure $c$-PEG with $\mathrm{HO}-\mathrm{PEG}-\mathrm{OH}$ and $\mathrm{MeO}-\mathrm{PEG}-\mathrm{OMe}$, along with $\mathrm{HS}-\mathrm{PEG}-$ OMe and HS-PEG-SH, allowed for the stringent evaluation of the effects from the topology and the end groups.

Dispersion stability against freezing, lyophilization, heating, and a physiological condition. Based on the enhanced stability of the micelles form the cyclic block copolymers ${ }^{20-22}$, we tested $c$-PEG for the dispersion stabilization of AuNPs in comparison with the linear counterparts, finding significantly enhanced stability against temperature and change in the phase. Thus, HO-PEG $3 \mathrm{k}-\mathrm{OH}, \mathrm{MeO}-\mathrm{PEG}_{3 \mathrm{k}}-\mathrm{OMe}$, HS-PEG ${ }_{3 \mathrm{k}}-\mathrm{OMe}$, or $c-\mathrm{PEG}_{3 \mathrm{k}}$ was added to a commercially available aqueous dispersion of AuNPs with $15 \mathrm{~nm}$ in diameter $\left(\mathrm{AuNPs}_{15}\right)$. By mixing AuNPs with these polymers, no change in the red color by the SPR absorption was observed. UV-Vis spectroscopy showed similar spectra to those before mixing with PEG, and $\lambda_{\max }$ remained at around $520 \mathrm{~nm}$ (Supplementary Fig. 6). Upon freezing in a household refrigerator, $A_{u N P s}{ }_{15}$ without PEG $\left(\right.$ AuNPs $_{15} / \mathrm{No}$ PEG) become nearly colorless due to aggregation ${ }^{13}$ and etching by dissolved oxygen (Fig. 2a) ${ }^{28}$. When AuNPs with $\mathrm{HO}-\mathrm{PEG}_{3 \mathrm{k}}-\mathrm{OH} \quad\left(\mathrm{AuNP}_{15} / \mathrm{HO}-\mathrm{PEG}_{3 \mathrm{k}}-\mathrm{OH}\right)$ and with $\mathrm{MeO}-\mathrm{PEG}_{3 \mathrm{k}}-\mathrm{OMe}\left(\mathrm{AuNPs}_{15} / \mathrm{MeO}-\mathrm{PEG}_{3 \mathrm{k}}-\mathrm{OMe}\right)$ were frozen, the red color of AuNPs disappeared and became grayish blue. After melting, UV-Vis spectra were recorded showing a strong bathochromic shift in $\lambda_{\max }\left(\mathrm{AuNPs}_{15} / \mathrm{HO}-\mathrm{PEG}_{3 \mathrm{k}}-\mathrm{OH}, 667 \mathrm{~nm}\right.$; $\left.\mathrm{AuNPs}_{15} / \mathrm{MeO}-\mathrm{PEG}_{3 \mathrm{k}}-\mathrm{OMe}, 687 \mathrm{~nm}\right)$, suggesting aggregation of 
a<smiles>COCCOCCOCCOCCOCCOCCOCCO</smiles>

d

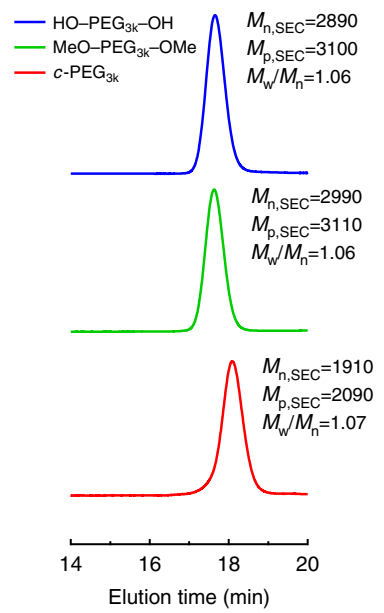

b

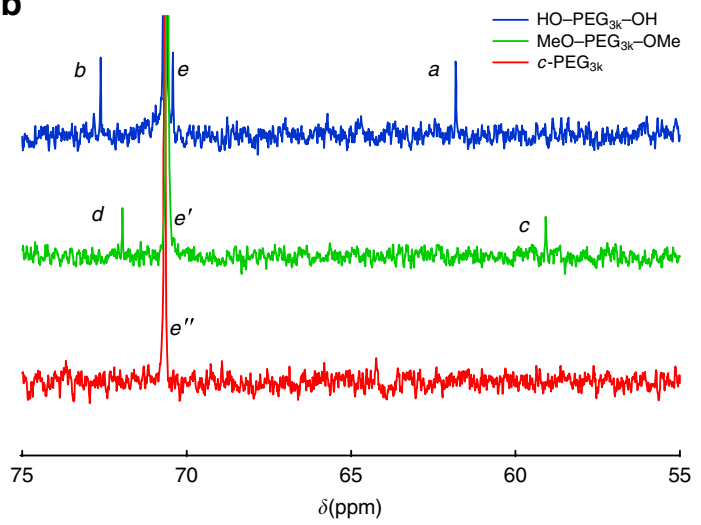

C

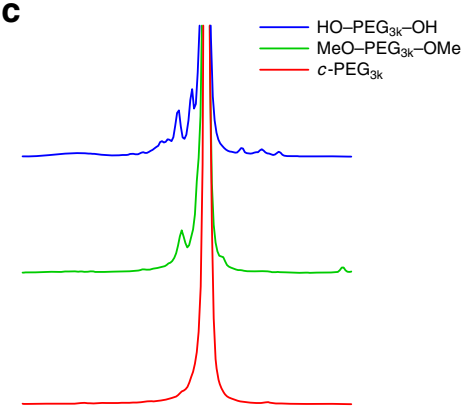

e
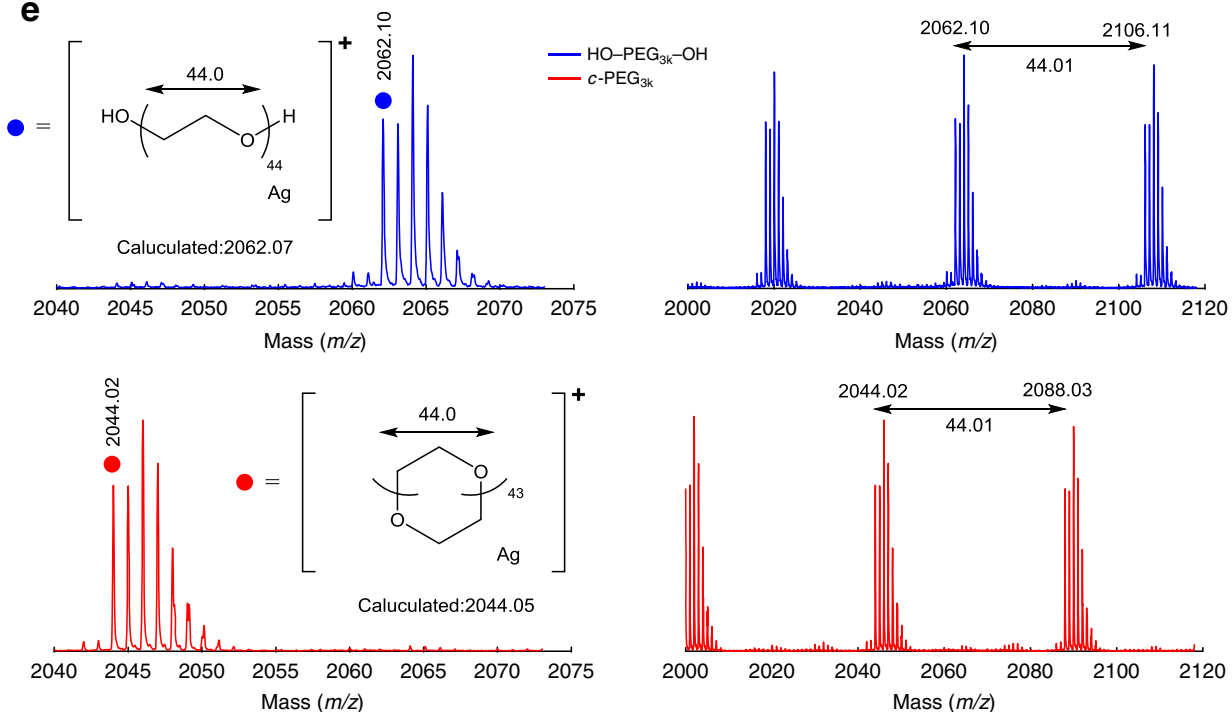

Fig. 1 Characterisation data for $\mathbf{H O}-\mathbf{P E G}_{\mathbf{3 k}}-\mathbf{O H}, \mathbf{M e O}-\mathbf{P E G}_{\mathbf{3 k}}-\mathbf{O M e}$, and $\mathbf{c}-\mathbf{P E G}_{\mathbf{3 k} \mathbf{k}}$ a Chemical structures, b ${ }^{13} \mathrm{C}$ NMR spectra, $\mathbf{c}{ }^{1} \mathrm{H} N M R$ spectra, $\mathbf{d}$ SEC traces, and e MALDI-TOF mass spectra of $\mathrm{HO}-\mathrm{PEG}_{3 \mathrm{k}}-\mathrm{OH}$ (blue), $\mathrm{MeO}-\mathrm{PEG}_{3 \mathrm{k}}-\mathrm{OMe}$ (green), and c- $\mathrm{PEG}_{3 \mathrm{k}}$ (red).

Table 1 Properties of PEG by SEC.

\begin{tabular}{|c|c|c|c|c|}
\hline Polymer & $\begin{array}{l}M_{\mathrm{n}, \mathrm{SEC}}^{\mathrm{a}} \\
\left(\mathrm{g} \mathrm{mol}^{-1}\right)\end{array}$ & $\begin{array}{l}M_{\mathrm{p}, \mathrm{SEC}}^{\mathrm{a}} \\
\left(\mathrm{g} \mathrm{mol}^{-1}\right)\end{array}$ & $M_{w} / M_{n}$ & $\begin{array}{l}\text { Ideal diameter } \\
\text { of } c \text {-PEG (nm) }\end{array}$ \\
\hline $\mathrm{HO}-\mathrm{PEG}_{1 \mathrm{k}}-\mathrm{OH}$ & 860 & 1220 & 1.35 & - \\
\hline$c-P G_{1 k}$ & 430 & 520 & 1.38 & 2.2 \\
\hline $\mathrm{HO}-\mathrm{PEG}_{3 \mathrm{k}}-\mathrm{OH}$ & 2890 & 3100 & 1.06 & - \\
\hline $\mathrm{MeO}-\mathrm{PEG}_{3 \mathrm{k}}-\mathrm{OMe}$ & 2990 & 3110 & 1.06 & - \\
\hline $\mathrm{HS}-\mathrm{PEG}_{3 \mathrm{k}}-\mathrm{OMe}$ & 2500 & 2540 & 1.07 & - \\
\hline $\mathrm{HS}-\mathrm{PEG}_{2 \mathrm{k}}-\mathrm{SH}$ & 2220 & 2500 & 1.08 & \\
\hline$c-P_{3 k}$ & 1910 & 2090 & 1.07 & 7.4 \\
\hline $\mathrm{HO}-\mathrm{PEG}_{5 \mathrm{k}}-\mathrm{OH}$ & 5450 & 5480 & 1.03 & - \\
\hline $\mathrm{MeO}-\mathrm{PEG}_{5 \mathrm{k}}-\mathrm{OMe}$ & 5460 & 5480 & 1.03 & - \\
\hline$c-P E G_{5 k}$ & 3750 & 3860 & 1.05 & 14 \\
\hline $\mathrm{HO}-\mathrm{PEG}_{10 \mathrm{k}}-\mathrm{OH}$ & 10,800 & 11,060 & 1.01 & - \\
\hline $\mathrm{MeO}-\mathrm{PEG}_{10 \mathrm{k}}-\mathrm{OMe}$ & 11,760 & 12,140 & 1.01 & - \\
\hline$c-P G_{10 k}$ & 8500 & 8810 & 1.02 & 28 \\
\hline
\end{tabular}

AuNPs. The relative absorption intensity (Rel. Abs) compared to that before freezing was $26 \%$ or less for these three specimens listed in Table 2. In contrast, the red color of AuNPs 15 HS-PEG ${ }_{3 \mathrm{k}}-\mathrm{OMe}$ (Rel. Abs $=92 \%$ ) and $\mathrm{AuNP}_{15} / c-\mathrm{PEG}_{3 \mathrm{k}}$ (Rel. Abs $=97 \%)$ persisted after melting with an unnoticeable change, and UV-Vis showed nearly identical spectra to those before freezing, demonstrating that the PEGylation by the two methods provide dispersibility through the frozen state.

Based on the above results, the effects of lyophilization of the dispersions were evaluated (Fig. 2b). In this experiment, the dispersions were frozen in liquid nitrogen, and the solvent was sublimed under reduced pressure. Dried AuNPs $s_{15} / \mathrm{HS}-\mathrm{PEG}_{3 \mathrm{k}}-\mathrm{OMe}$ and $\mathrm{AuNPs}_{15} / c-\mathrm{PEG}_{3 \mathrm{k}}$ kept the red color, suggesting that AuNPs did not aggregate even in the solid state likely by the respective PEG molecules penetrate among AuNPs. Upon addition of water, AuNPs $_{15} / \mathrm{HS}-\mathrm{PEG}_{3 \mathrm{k}}-\mathrm{OMe}$ (Rel. Abs $=84 \%$ ) and $\mathrm{AuNPs}_{15} / c$ $\mathrm{PEG}_{3 \mathrm{k}}$ (Rel. Abs $=91 \%$ ) gave a redispersion with good restoration

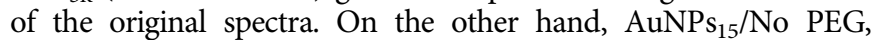
$\mathrm{AuNP}_{15} / \mathrm{HO}-\mathrm{PEG}_{3 \mathrm{k}}-\mathrm{OH}$, and $\mathrm{AuNP}_{15} / \mathrm{MeO}-\mathrm{PEG}_{3 \mathrm{k}}-\mathrm{OMe}$ formed grayish blue solid, and redispersion was not possible (Rel. Abs $\leq 9 \%)$. These experiments indicate that the physisorption of $c$ PEG can endow AuNPs with dispersion stability against freezing and lyophilization as good as the chemisorption of HS-PEG-OMe.

Furthermore, AuNPs $s_{15} / \mathrm{No}$ PEG, AuNPs ${ }_{15} / \mathrm{HO}-\mathrm{PEG}_{3 \mathrm{k}}-\mathrm{OH}$, AuNPs $_{15} / \mathrm{MeO}-\mathrm{PEG}_{3 \mathrm{k}}-\mathrm{OMe}, \mathrm{AuNPs}_{15} / \mathrm{HS}-\mathrm{PEG}_{3 \mathrm{k}}-\mathrm{OMe}$, and $\mathrm{AuNPs}_{15} / c-\mathrm{PEG}_{3 \mathrm{k}}$ were heated at $85^{\circ} \mathrm{C}$ for $4 \mathrm{~h}$ to determine the thermal stability. Most of the nanoparticles in $\mathrm{AuNPs}_{15} /$ $\mathrm{MeO}-\mathrm{PEG}_{3 \mathrm{k}}-\mathrm{OMe}$ (Rel. Abs =12\%) and $\mathrm{AuNPs}_{15} /$ HS-PEG $3 \mathrm{k}-\mathrm{OMe}($ Rel. Abs $=13 \%)$ aggregated to deposit or etched by dissolved oxygen to give almost colorless liquid (Fig. 2c) ${ }^{28}$. AuNPs ${ }_{15} /$ No PEG (Rel. Abs = 39\%) and AuNPs A $_{15} /$ $\mathrm{HO}-\mathrm{PEG}_{3 \mathrm{k}}-\mathrm{OH}$ (Rel. Abs $=78 \%$ ) showed some degree of retention of the red color but less intense than those before 


\section{a Freezing}

Before freezing

HO-PEG-OH HS-PEG-OMe

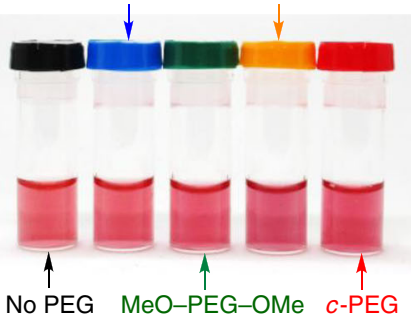

After freezing

HO-PEG-OH HS-PEG-OMe

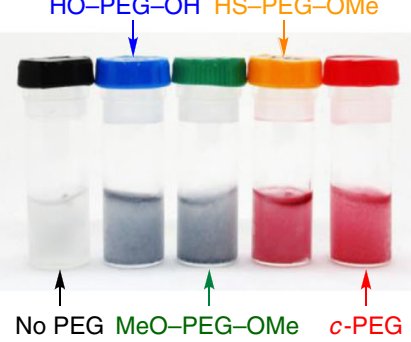

After melting

HO-PEG-OH HS-PEG-OMe

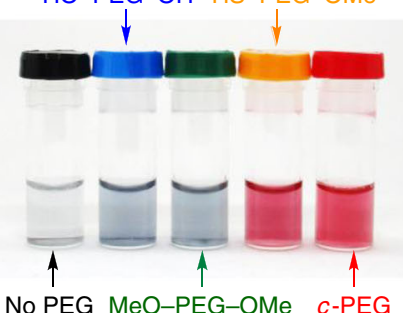

No PEG MeO-PEG-OMe $\quad c$-PEG

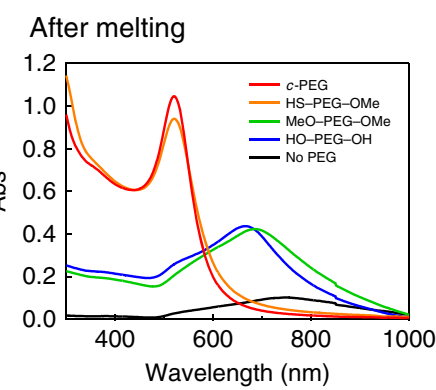

\section{b Lyophilization}

Before lyophilization HO-PEG-OH HS-PEG-OMe

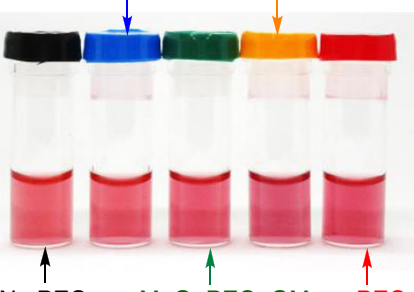

No PEG MeO-PEG-OMe $c$-PEG

After lyophilization

HO-PEG-OH HS-PEG-OMe
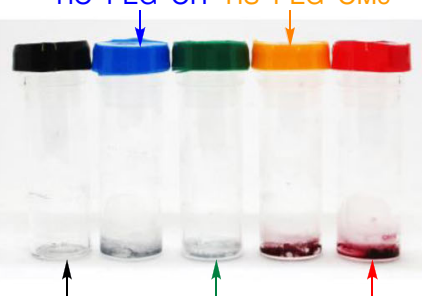

No PEG MeO-PEG-OMe $c$-PEG

\section{After redispersion}

HO-PEG-OH HS-PEG-OMe

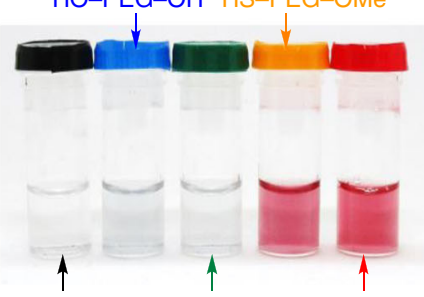

No PEG MeO-PEG-OMe $\quad c$-PEG

After redispersion

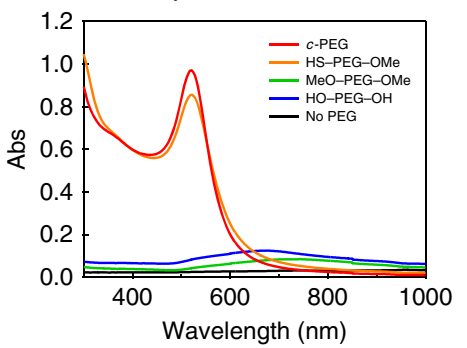

\section{c Heating}

Before heating

HO-PEG-OH HS-PEG-OMe

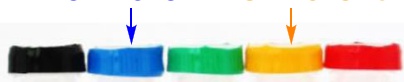

1

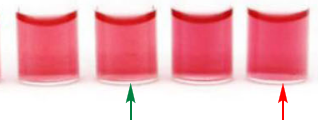

No PEG MeO-PEG-OMe c-PEG

After heating

HO-PEG-OH HS-PEG-OMe
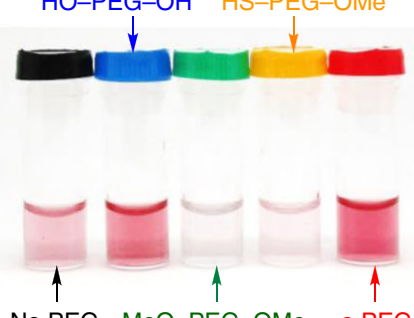

No PEG MeO-PEG-OMe c-PEG

Before heating

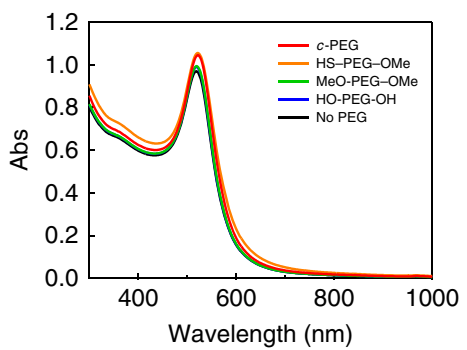

After heating

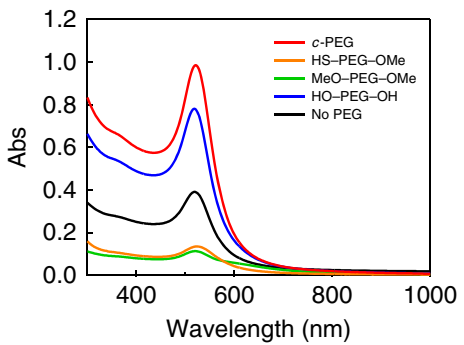

Fig. 2 Freezing, lyophilization, and heating tests. Photographs and UV-Vis spectra of AuNPs $s_{15} /$ No PEG (black), AuNPs $s_{15} / H_{O}-P E G_{3 k}-O H$ (blue), AuNPs $s_{15} / \mathrm{MeO}-\mathrm{PEG}_{3 \mathrm{k}}-\mathrm{OMe}$ (green), AuNPs $\mathrm{s}_{15} / \mathrm{HS}-\mathrm{PEG}_{3 \mathrm{k}}-\mathrm{OMe}$ (orange), and $\mathrm{AuNPs}_{15} / \mathrm{c}-\mathrm{PEG}_{3 \mathrm{k}}$ (red). a Freezing test using a household refrigerator. From top to bottom, photographs before freezing, after freezing, after melting, and a UV-Vis spectrum after melting. $\mathbf{b}$ Lyophilization test using liquid $\mathrm{N}_{2}$. From top to bottom, photographs before freezing, after lyophilization, after redispersion, and a UV-Vis spectrum after redispersion. The UV-Vis spectra before freezing and lyophilization are shown in Supplementary Fig. 6 . c Heating test at $85^{\circ} \mathrm{C}$ for $4 \mathrm{~h}$. From top to bottom, photographs before and after heating and UV-Vis spectra before and after heating.

Table 2 Relative absorption intensity (Rel. Abs) of $\mathrm{AuNPs}_{15} / \mathrm{PEG}_{3 \mathrm{k}}$ in freezing, lyophilization, heating, and physiological condition tests.

\begin{tabular}{|c|c|c|c|c|c|}
\hline Test & No PEG & HO-PEG-OH & MeO-PEG-OMe & HS-PEG-OMe & c-PEG \\
\hline Freezing & $3 \%$ & $26 \%$ & $21 \%$ & $92 \%$ & $97 \%$ \\
\hline Heating & $39 \%$ & $78 \%$ & $12 \%$ & $13 \%$ & $95 \%$ \\
\hline
\end{tabular}


a Before heating
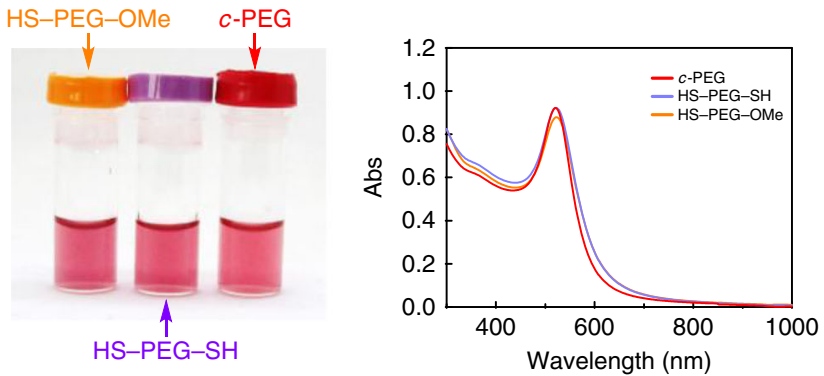

b After heating for $4 \mathrm{~h}$

c After heating for $8 \mathrm{~h}$
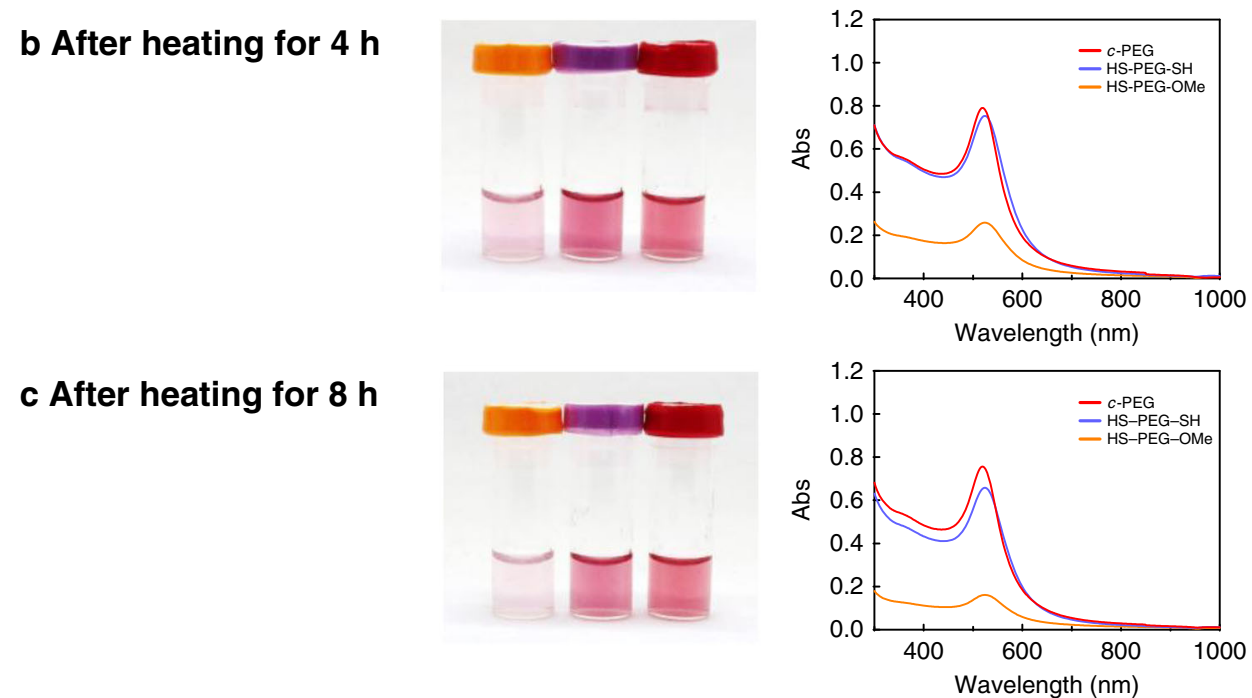

d After heating for $12 \mathrm{~h}$
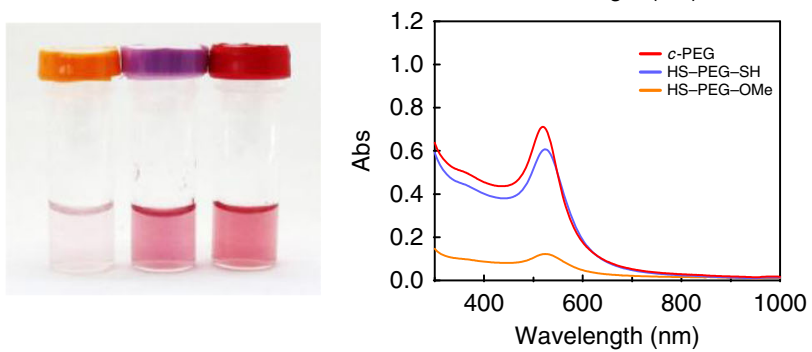

e After heating for $24 \mathrm{~h}$
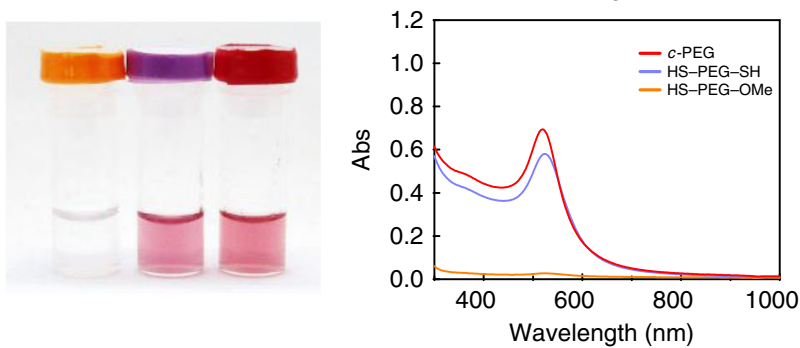

\section{f After heating for $48 \mathrm{~h}$}
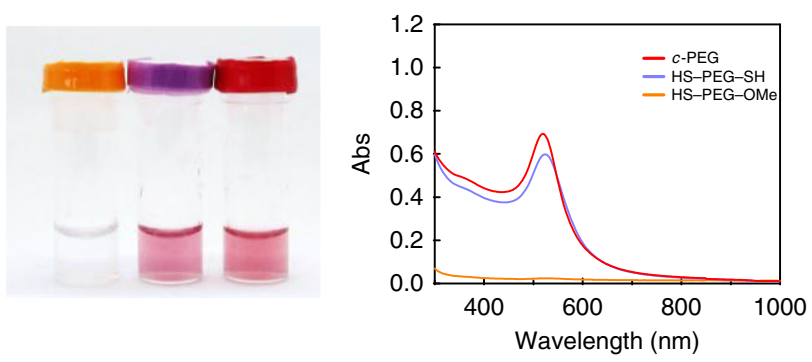

Fig. 3 Time course heating test. Photographs and UV-Vis spectra of AuNPs $s_{15} / H S-P E G_{3 k}-O M e$ (orange), AuNPs $15 / H S-P E G_{2 k}-S H$ (purple), and $\mathrm{AuNPs}_{15} / \mathrm{c}-\mathrm{PEG}_{3 \mathrm{k}}$ (red). a Before heating and after heating for b 4, c 8, d 12, e 24, and $\mathbf{f} 48 \mathrm{~h}$ at $85^{\circ} \mathrm{C}$. Rel. Abs was $2 \%$ for AuNPs $15 / \mathrm{HS}-\mathrm{PEG}_{3 \mathrm{k}}-\mathrm{OMe}$, $64 \%$ for $\mathrm{AuNPs}_{15} / \mathrm{HS}-\mathrm{PEG}_{2 \mathrm{k}}-\mathrm{SH}$, and $75 \%$ for $\mathrm{AuNPs}_{15} / \mathrm{c}-\mathrm{PEG}_{3 \mathrm{k}}$ after $48 \mathrm{~h}$. 


\section{a Before adding PBS}

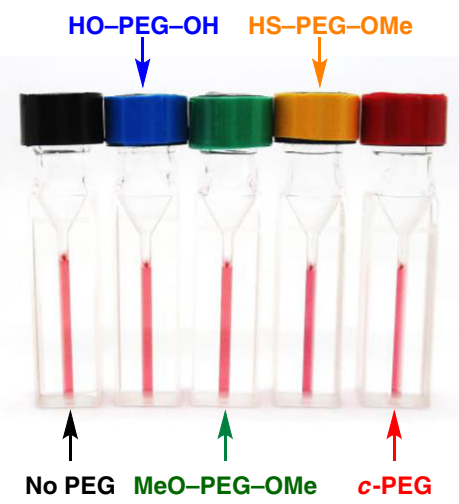

b Immediately after adding PBS

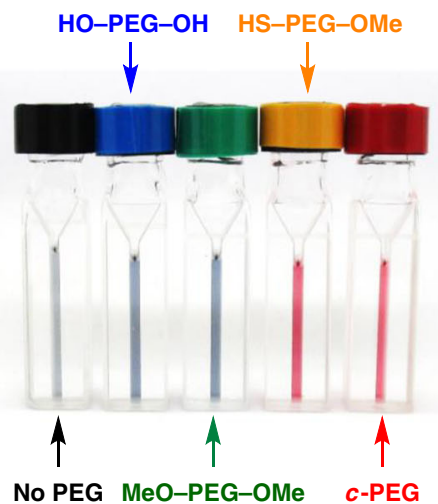

c 1000 min after adding PBS

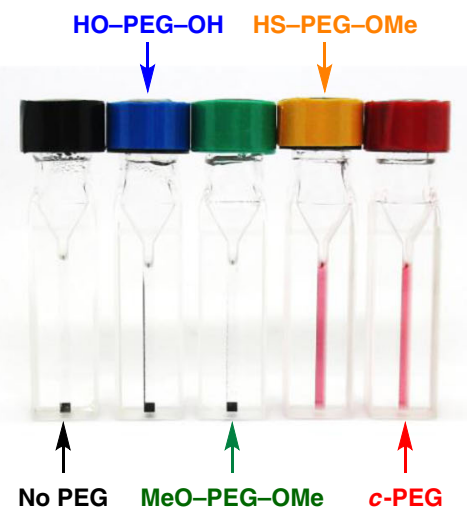

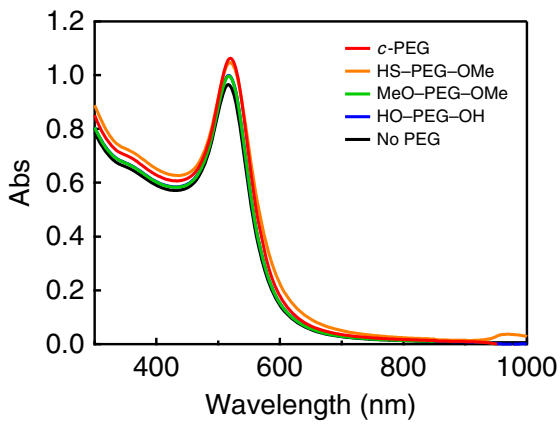
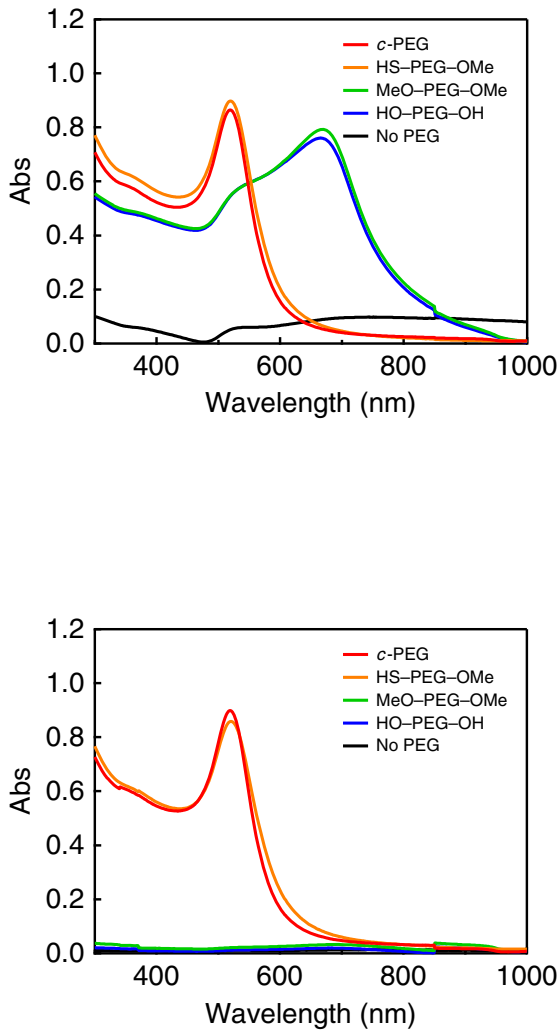

Fig. 4 Physiological condition test. Photographs and UV-Vis spectra of AuNPs $s_{15} /$ No PEG (black), AuNPs $s_{15} / \mathrm{HO}-\mathrm{PEG}_{3 \mathrm{k}}-\mathrm{OH}$ (blue), AuNPs $15 /$ $\mathrm{MeO}-\mathrm{PEG}_{3 \mathrm{k}}-\mathrm{OMe}$ (green), AuNPs $15 / \mathrm{HS}-\mathrm{PEG}_{3 \mathrm{k}}-\mathrm{OMe}$ (orange), and $\mathrm{AuNPs}_{15} / \mathrm{c}-\mathrm{PEG}_{3 \mathrm{k}}$ (red). a Before, b immediately after, and $\mathbf{c} 1000 \mathrm{~min}$ after the addition of a tenfold-concentrated PBS solution. The resulting dispersions were $\mathrm{pH} 7.4$ and $150 \mathrm{mM}$ of NaCl.

heating. Interestingly, the color and UV-Vis spectrum of $\mathrm{AuNPs}_{15} / c-\mathrm{PEG}_{3 \mathrm{k}}$ were nearly intact (Rel. Abs $=95 \%$ ), suggesting excellent dispersion stability against heating.

In order to determine the cause of the relatively poor protection by $\mathrm{HS}-\mathrm{PEG}_{3 \mathrm{k}}-\mathrm{OMe}$ against heating, ${ }^{1} \mathrm{H}$ NMR was used to find that the thiol group turned into disulfide $\left(-\mathrm{CH}_{2}-\mathrm{S}-\mathrm{S}-\mathrm{CH}_{2}-, 2.91\right.$ ppm) (Supplementary Fig. 7). ${ }^{13} \mathrm{C}$ NMR before and after heating also suggests the formation of disulfide (Supplementary Fig. 8). It is known that the bonding of $\mathrm{Au}$ and HS-PEG is dynamic ${ }^{29}$, and we expected that at high temperature, $\mathrm{HS}-\mathrm{PEG}_{3 \mathrm{k}}-\mathrm{OMe}$ is liberated from the surface of AuNPs and oxidized to form disulfide (MeO-PEG $\left.3 \mathrm{k}-\mathrm{S}-\mathrm{S}-\mathrm{PEG}_{3 \mathrm{k}}-\mathrm{OMe}\right)$. Once disulfide is formed, the affinity to $\mathrm{Au}$ becomes much smaller than that of thiol $^{30}$, leading to the less shielding on AuNPs. In the meantime, $\mathrm{HO}-\mathrm{PEG}_{3 \mathrm{k}}-\mathrm{OH}$ showed moderate dispersion stability most likely by the effects of the hydroxy chain end groups.

Furthermore, AuNPs ${ }_{15} / \mathrm{HS}-\mathrm{PEG}_{2 \mathrm{k}}-\mathrm{SH}$ was also tested against heating at $85^{\circ} \mathrm{C}$, where the polymers are anchored to the surface at both chain ends (Fig. 3) 31,32 . After 48 h, Rel. Abs was only $2 \%$ for $\mathrm{AuNPs}_{15} / \mathrm{HS}-\mathrm{PEG}_{3 \mathrm{k}}-\mathrm{OMe}, 64 \%$ for AuNPs $\mathrm{s}_{15} / \mathrm{HS}-\mathrm{PEG}_{2 \mathrm{k}}-\mathrm{SH}$, and $75 \%$ for $\mathrm{AuNPs}_{15} / c-\mathrm{PEG}_{3 \mathrm{k}}$. Both $\mathrm{AuNPs}_{15} / \mathrm{HS}-\mathrm{PEG}_{2 \mathrm{k}}-\mathrm{SH}$ and $\mathrm{AuNPs}_{15} / c-\mathrm{PEG}_{3 \mathrm{k}}$ showed good long-term stability at high temperature. The high stability of $\mathrm{AuNPs}_{15} / \mathrm{HS}-\mathrm{PEG}_{2 \mathrm{k}}-\mathrm{SH}$ was likely caused by that even when one chain end of HS-PEG-SH is 


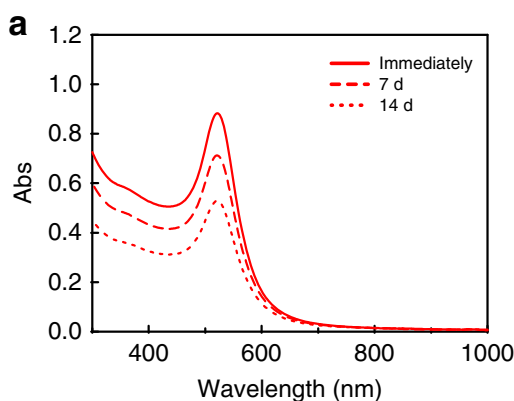

C
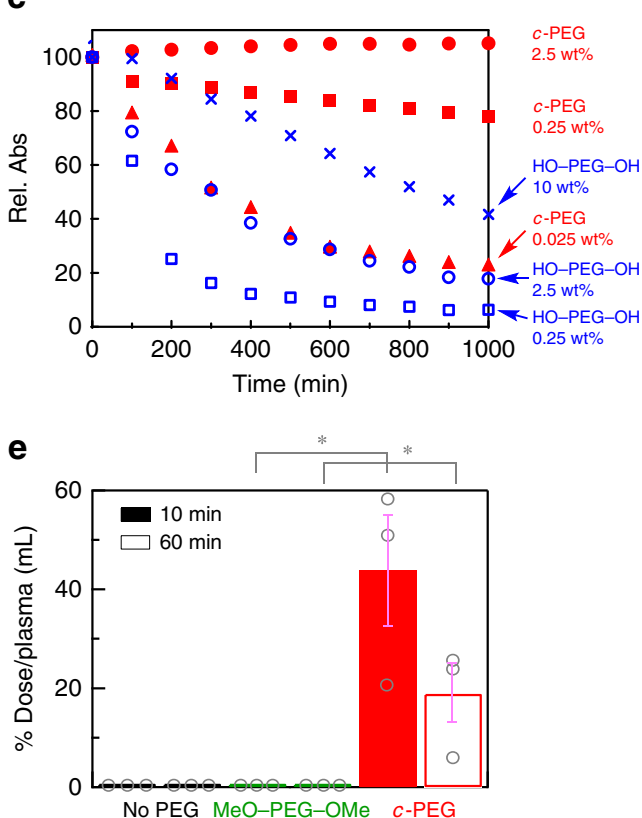

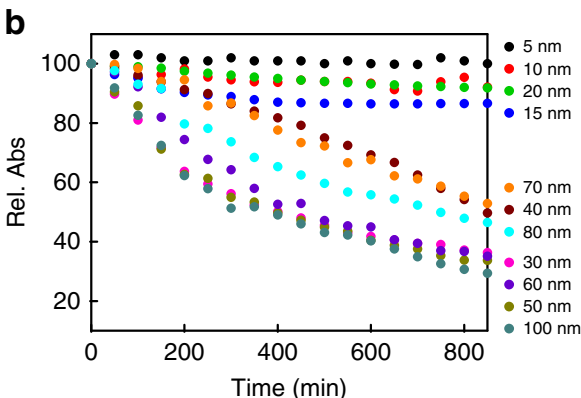

d

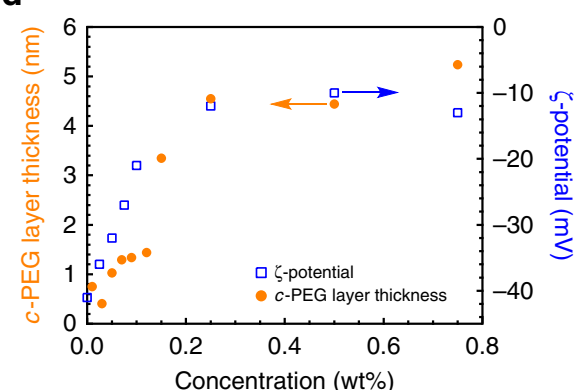

f

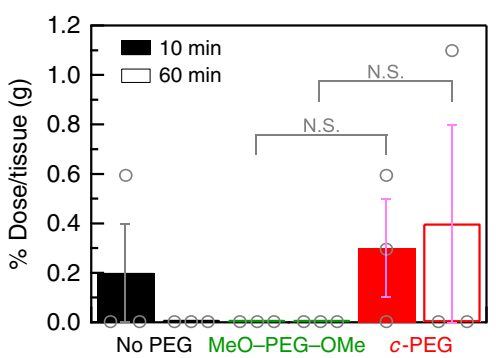

Fig. 5 Properties of AuNPs/PEG. a UV-Vis spectra of $A u N P s_{15} / c-P E G_{3 k}$ immediately after, $7 \mathrm{~d}$ after, and $14 \mathrm{~d}$ after the addition of a tenfold-concentrated PBS solution. Rel. Abs was $81 \%$ after $7 \mathrm{~d}$ and $60 \%$ after $14 \mathrm{~d}$. b Time course of Rel. Abs of AuNPs/c-PEG $3 \mathrm{k}$ in a physiological condition of pH 7.4 and 150 $\mathrm{mM}$ of $\mathrm{NaCl}$. The diameter of AuNPs was $5-100 \mathrm{~nm}$. c Time course of Rel. Abs of AuNPs $s_{5}$ in the physiological condition in the presence of $\mathrm{HO}^{-} \mathrm{PEG}_{5 \mathrm{k}}-\mathrm{OH}$ or c- $\mathrm{PEG}_{5 \mathrm{k}}$ with various concentrations. $\mathrm{HO}-\mathrm{PEG}_{5 \mathrm{k}}-\mathrm{OH}, 0.25 \mathrm{wt} \%$ (blue square); $2.5 \mathrm{wt} \%$ (blue circle); 10 wt $\%$ (blue cross). c- $\mathrm{PEG}$ 5k, $0.025 \mathrm{wt} \%$ (red triangle); $0.25 \mathrm{wt} \%$ (red square); $2.5 \mathrm{wt} \%$ (red circle). d c-PEG layer thickness and $\zeta$-potential for $\mathrm{AuNPs}_{15} / \mathrm{c}-\mathrm{PEG} \mathrm{G}_{3 \mathrm{k}}$ with various concentration of c-PEG $\mathrm{dk}_{3 \mathrm{k}}$.

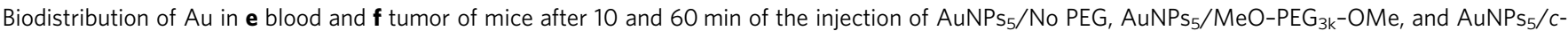
$\mathrm{PEG}_{3 \mathrm{k}}$. Data represent mean \pm s.e. from three independent experiments performed in triplicate. ${ }^{\star} p<0.05 ; \mathrm{N} . \mathrm{S}$. $=$ not significant. Source data for $(\mathbf{e}, \mathbf{f})$ are provided as a Source data file.

liberated from the surface of AuNPs by heating, the polymer is held by other chain end, preventing the complete removal from AuNPs. In any case, $c-\mathrm{PEG}_{3 \mathrm{k}}$ gave the best result. All of the above experiments suggest that $c$-PEG endows AuNPs with significant dispersion stability against freezing, lyophilization, and heating.

In addition, mixtures of $c$-PEG with $\mathrm{MeO}-\mathrm{PEG}-\mathrm{OMe}$ or HS-PEG-OMe were tested against heating. Thus, $\mathrm{MeO}-\mathrm{PEG}_{3 \mathrm{k}}-\mathrm{OMe}(0.225,0.125$, or $0.025 \mathrm{wt} \%)$ and $c-\mathrm{PEG}_{3 \mathrm{k}}$ $(0.025,0.125$, or $0.225 w t \%$, respectively) were added to AuNPs 30 to form AuNPs $s_{30} / \mathrm{MeO}-\mathrm{PEG}_{3 \mathrm{k}}-\mathrm{OMe} / \mathrm{c}-\mathrm{PEG}_{3 \mathrm{k}}$ with a total PEG concertation of $0.25 \mathrm{wt} \%$. The mixtures were heated at $85^{\circ} \mathrm{C}$ for 4 $\mathrm{h}$, resulting in an increase of Rel. Abs with the proportion of $c$ PEG (Rel. Abs $=67,76$, or $81 \%$, respectively) shown in Supplementary Fig. 9. When HS-PEG $3 \mathrm{k}-\mathrm{OMe}(0.225,0.125$, or $0.025 \mathrm{wt} \%)$ and $c-\mathrm{PEG}_{3 \mathrm{k}}(0.025,0.125$, or $0.225 \mathrm{wt} \%$, respectively) were used, Rel. Abs significantly decreased even for the lowest concentration of HS-PEG ${ }_{3 \mathrm{k}}-\mathrm{OMe}$ (Rel. Abs $=17,17$, or $46 \%$, respectively) shown in Supplementary Fig. 10. This indicates that the presence of thiol and/or disulfide at high temperature stimulates the dissolution of AuNPs, and thus HS-PEG-OMe is not a proper capping agent against heating.
Physiological conditions, which contain $\mathrm{NaCl}$ and other electrolytes, are also known to cause aggregation due to the increased ionic strength to form a salt with the citrate on the AuNPs surface to partially neutralize the charges ${ }^{13,33}$. Based on the discovered enhanced dispersion stability of AuNPs provided by $c$-PEG, that in a physiological condition was examined for potential biological applications. Thus, the dispersion stability of $\mathrm{AuNP}_{15} / \mathrm{No}$ PEG, AuNPs $\mathrm{s}_{15} / \mathrm{HO}-\mathrm{PEG}_{3 \mathrm{k}}-\mathrm{OH}, \mathrm{AuNPs}_{15} /$ $\mathrm{MeO}-\mathrm{PEG}_{3 \mathrm{k}}-\mathrm{OMe}, \mathrm{AuNPs}_{15} / \mathrm{HS}-\mathrm{PEG}_{3 \mathrm{k}}-\mathrm{OMe}$, and $\mathrm{AuNP}_{15} / c$ $\mathrm{PEG}_{3 \mathrm{k}}$ was tested at a typical physiological condition of $\mathrm{pH}=7.4$ and $150 \mathrm{mM}$ of $\mathrm{NaCl}$. A tenfold-concentrated phosphate buffer saline (PBS) solution $(0.06 \mathrm{~mL})$ was added to the AuNPs s $_{15} / \mathrm{PEG}$ dispersions $(0.54 \mathrm{~mL})$ form the intended physiological condition. The color of $\mathrm{AuNPs}_{15} / \mathrm{No}$ PEG, AuNPs $\mathrm{s}_{15} / \mathrm{HO}-\mathrm{PEG}_{3 \mathrm{k}}-\mathrm{OH}$, and AuNPs $_{15} / \mathrm{MeO}-\mathrm{PEG}_{3 \mathrm{k}}-\mathrm{OMe}$ changed to grayish blue immediately after the addition of the concentrated PBS solution and eventually precipitated (Fig. 4). On the contrary, no color change was observed for AuNPs 15 /HS-PEG $3 \mathrm{k}-\mathrm{OMe}$ and $\mathrm{AuNPs}_{15} / \mathcal{c}$ $\mathrm{PEG}_{3 \mathrm{k}}$ even after $1000 \mathrm{~min}$. UV-Vis spectra showed that there is no absorption from the SPR of AuNPs ${ }_{15} / \mathrm{No}$ PEG, AuNPs $s_{15} /$ $\mathrm{HO}-\mathrm{PEG}_{3 \mathrm{k}}-\mathrm{OH}$, and $\mathrm{AuNPs}_{15} / \mathrm{MeO}-\mathrm{PEG}_{3 \mathrm{k}}-\mathrm{OMe}$ due to the 

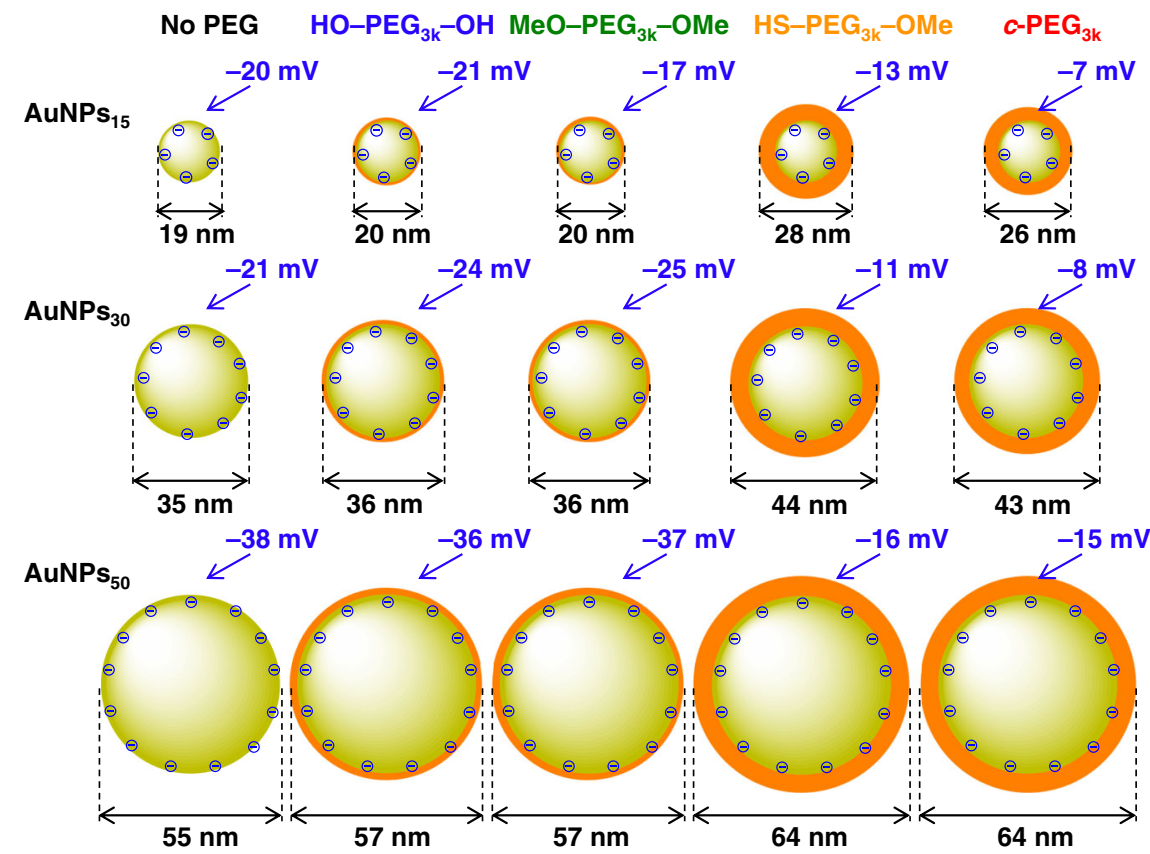

Fig. 6 Schematic illustrations of the DLS size and $\zeta$-potential of AuNPs/No PEG, AuNPs/HO-PEG 3 -OH, AuNPs/MeO-PEG 3 -OMe, AuNPs/ HS-PEG $\mathbf{3 k}-\mathbf{O M e}$, and AuNPs/c-PEG $\mathbf{3 k}$. The size of AuNPs was 15, 30, and 50 nm, and the concentration of PEG was 0.25 wt\%. The size ratio of AuNPs and the PEG layer in the figure represents the actual ratio.

precipitation (Rel. Abs $\leq 2 \%$ in Table 2), while AuNPs $_{15} /$ HS-PEG $3 \mathrm{k}-\mathrm{OMe}($ Rel. Abs $=83 \%)$ and $\mathrm{AuNPs}_{15} / c-\mathrm{PEG}_{3 \mathrm{k}}$ (Rel. Abs $=88 \%$ ) did not exhibited a significant change from those before the addition of the concentrated PBS solution. The slight decrease in Rel. Abs was caused by the dilution of the AuNPs dispersion $(0.54 \mathrm{~mL})$ with the concentrated PBS solution $(0.06$ $\mathrm{mL})$. It is assumed that the surface of AuNPs was protected by the physisorption of $c$-PEG not to contact with other nanoparticles even when AuNPs lose the repulsive surface charges by the increased ionic strength in the physiological condition, leading to the suppression of aggregation. Furthermore, $\mathrm{AuNPs}_{15} / c-\mathrm{PEG}_{3 \mathrm{k}}$ was kept under the physiological condition at $37^{\circ} \mathrm{C}$ for an extended period. Rel. Abs was $81 \%$ after $7 \mathrm{~d}$ and $60 \%$ after $14 \mathrm{~d}$, exhibiting a reasonable long-term stability (Fig. 5a and Supplementary Fig. 11).

The size-dependence of AuNPs was then examined by varying from 5 to $100 \mathrm{~nm}$ using $c$ - $\mathrm{PEG}_{3 \mathrm{k}}$ for the physiological condition test. In the result, $\mathrm{AuNPs}_{20}$ and smaller sizes persisted dispersion in the presence of $c-\mathrm{PEG}_{3 \mathrm{k}}$ (Fig. 5b and Supplementary Fig. 12). On the other hand, AuNPs 30 and larger sizes were not sufficiently stabilized, and the color fainted after $850 \mathrm{~min}$. It is known that AuNPs with a smaller size form a more stable dispersion, and the dispersion stability gradually decreases by increasing the size ${ }^{14}$. Thus, $c-\mathrm{PEG}_{3 \mathrm{k}}$, which has a diameter of $7.4 \mathrm{~nm}$ when the molecule forms an ideal right circular conformation, showed sizedependent stabilization with a threshold between $\mathrm{AuNP}_{20}$ and AuNPs $_{30}$. Additionally, the dependence on the $c$-PEG size was also tested by using $c$-PEG $1 \mathrm{k}, c-\mathrm{PEG}_{5 \mathrm{k}}$, and $c$ - $\mathrm{PEG}_{10 \mathrm{k}}$ with a diameter of $2.2,14$, and $28 \mathrm{~nm}$, respectively (Table 1 ). However, no significant difference was observed (Supplementary Fig. 13); all of $c-\mathrm{PEG}_{1 \mathrm{k}}, c-\mathrm{PEG}_{5 \mathrm{k}}$, and $c$ - $\mathrm{PEG}_{10 \mathrm{k}}$ gave enhanced dispersion stability to AuNPs ${ }_{15}$. On the contrary, 18-crown-6 ether with molecular weight of $264 \mathrm{Da}$ with $0.7 \mathrm{~nm}$ in the estimated diameter did not give dispersion stability, and $\mathrm{AuNPs}_{15}$ completely precipitated. Thus, the dispersion stabilization depended on both sizes of AuNPs and c-PEG.

Moreover, the PEG concentration-dependence of the dispersion stability was investigated. The $c-\mathrm{PEG}_{5 \mathrm{k}}$ concentration was changed from 0.025 to $2.5 \mathrm{wt} \%$ for $\mathrm{AuNPs}_{5}(0.05 \mathrm{mg} / \mathrm{mL})$ in the physiological condition. As shown in Fig. $5 c$, Rel. Abs decreased to $22 \%$ after $1000 \mathrm{~min}$ for $c-\mathrm{PEG}_{5 \mathrm{k}}$ solutions with $0.025 \mathrm{wt} \%$. However, when the $c$-PEG concertation was $0.25 \mathrm{wt} \%$, the decrease in Rel. Abs was suppressed to $78 \%$. In the case of 2.5 wt $\%$ of $c$ - PEG $_{5 \mathrm{k}}$, the absorption essentially quantitatively remained. In this regard, the weight ratio of $\mathrm{AuNP}_{5} / \mathrm{PEG}$ was $1 / 500$ for $2.5 \mathrm{wt} \%$ of the PEG concentration. The concentrationdependence of $\mathrm{HO}-\mathrm{PEG}_{5 \mathrm{k}}-\mathrm{OH}$ was also tested for comparison. In the result, the absorption spectra of $\mathrm{AuNPs}_{5} / \mathrm{HO}-\mathrm{PEG}_{5 \mathrm{k}}-\mathrm{OH}$ showed a strong declination even with the PEG concentration of $10 \mathrm{wt} \%$ (Rel. Abs $=42 \%)$.

DLS and $\zeta$-potential. In order to investigate the cause of the dispersion stabilization by $c$-PEG, DLS and $\zeta$-potentials were measured using $\mathrm{AuNPs}_{15}, \mathrm{AuNPs}_{30}$, and AuNPs 50 with no PEG, $\mathrm{HO}-\mathrm{PEG}_{3 \mathrm{k}}-\mathrm{OH}, \mathrm{MeO}-\mathrm{PEG}_{3 \mathrm{k}}-\mathrm{OMe}, \mathrm{HS}-\mathrm{PEG}_{3 \mathrm{k}}-\mathrm{OMe}$, and $c$ $\mathrm{PEG}_{3 \mathrm{k}}$ at a polymer concentration of $0.25 \mathrm{wt} \%$. The DLS size was nearly identical or slightly increased by $2 \mathrm{~nm}$ or less upon the addition of $\mathrm{HO}-\mathrm{PEG}_{3 \mathrm{k}}-\mathrm{OH}$ and $\mathrm{MeO}-\mathrm{PEG}_{3 \mathrm{k}}-\mathrm{OMe}$ compared to corresponding AuNPs/No PEG (Fig. 6). In the case of AuNPs ${ }_{15}$, the diameter was $19 \mathrm{~nm}$ for AuNPs $s_{15} /$ No PEG and $20 \mathrm{~nm}$ for $\mathrm{AuNPs}_{15} /$ $\mathrm{HO}-\mathrm{PEG}_{3 \mathrm{k}}-\mathrm{OH}$ and $\mathrm{AuNP}_{15} / \mathrm{MeO}-\mathrm{PEG}_{3 \mathrm{k}}-\mathrm{OMe}$. In contrast, by the addition of $\mathrm{HS}-\mathrm{PEG}_{3 \mathrm{k}}-\mathrm{OMe}$ or $c-\mathrm{PEG}_{3 \mathrm{k}}$, the size was significantly increased by $7 \mathrm{~nm}$ or more. For example, the diameter of $\mathrm{AuNPs}_{15}$ increased to 28 and $26 \mathrm{~nm}$ for $\mathrm{AuNPs}_{15} / \mathrm{HS}-\mathrm{PEG}_{3 \mathrm{k}}-\mathrm{OMe}$ and $\mathrm{AuNP}_{15} / c-\mathrm{PEG}_{3 \mathrm{k}}$, respectively. The similar trends in the change in the diameter were observed for AuNPs s $_{30}$ and AuNPs s0 $_{50}$, suggesting that $\mathrm{HS}-\mathrm{PEG}_{3 \mathrm{k}}-\mathrm{OMe}$ and $c$ - $\mathrm{PEG}_{3 \mathrm{k}}$ have a stronger affinity to the surface of AuNPs and form a thicker layer. Because the surface of AuNPs is coated with citrate, the $\zeta$-potential of AuNPs/No PEG showed negative values such as $-20 \mathrm{mV}$ for $\mathrm{AuNPs}_{15}$. It was reported that the electrically neutral PEG layer on the surface shields the negative charges of citrate to decrease in the magnitude of the $\zeta$-potential ${ }^{34}$. While the $\zeta$-potential of AuNPs/ $\mathrm{HO}-\mathrm{PEG}_{3 \mathrm{k}}-\mathrm{OH}$ and $\mathrm{AuNP} / \mathrm{MeO}-\mathrm{PEG}_{3 \mathrm{k}}-\mathrm{OMe}$ did not significantly change from corresponding AuNPs/No PEG, that of 
AuNPs/c- $-\mathrm{PEG}_{3 \mathrm{k}}$ strongly attenuated, which was even better shielding than AuNPs/HS-PEG $3 \mathrm{k}-\mathrm{OMe}$ in some cases such as $\mathrm{AuNPs}_{15} / \mathrm{HS}-\mathrm{PEG}_{3 \mathrm{k}}-\mathrm{OMe}(-13 \mathrm{mV})$ and $\mathrm{AuNPs}_{15} / c-\mathrm{PEG}_{3 \mathrm{k}}(-7$ $\mathrm{mV})$. Thus, the results of the increased diameter and reduced $\zeta$ potential for AuNPs/c-PEG suggest the strong interaction of $c$-PEG to AuNPs and the formation of a PEG layer with a decent density on the basis of the cyclic topology 24 .

Furthermore, the $c$-PEG concentration-dependence of the layer thickness and $\zeta$-potential were determined for $\mathrm{AuNPs}_{15} / c-\mathrm{PEG}_{3 \mathrm{k}}$ (Fig. 5d). Both of the thickness and $\zeta$-potential gradually increased and essentially saturated at around $4.5 \mathrm{~nm}$ and $-12 \mathrm{mV}$, respectively, at a PEG concentration of $0.25 \mathrm{wt} \%$, suggesting this concentration is optimal. The grafting density $(\sigma)$ was calculated based on the PEG layer thickness using the following formulae as reported in previous studies (Supplementary Table 2) ) $^{35-37}$. Thus, the surface concentration $(\Gamma)$, average distance between grafted PEG chains $(D)$, and $\sigma$ were calculated by:

$$
\begin{gathered}
\Gamma=\rho t \\
D=\left(M / \Gamma N_{\mathrm{A}}\right)^{1 / 2} \\
\sigma=(a / D)^{2}
\end{gathered}
$$

where $a$ is the size of a PEG monomer unit (3.5 $\AA$ ), $\rho$ is the density of PEG $(1.1 \mathrm{~g} / \mathrm{mL}), t$ is the thickness of the PEG layer by DLS, $N_{\mathrm{A}}$ is Avogadro's number, and $M$ is the molecular weight of PEG. Despite that the calculation is designated for chemisorption, we consider this helps deducing the state and environment of $c$-PEG at the AuNPs surface. In the result, $\sigma$ was found to be 0.13 chains/ $\mathrm{nm}^{2}$ at the $c$-PEG concentration of $0.25 \mathrm{wt} \%$. This value may be comparable to $0.20-3.14$ chains $/ \mathrm{nm}^{2}$ reported for HS-PEG-OMe that was determined by a different method, in which the adsorbed PEG molecules was quantitatively removed from AuNPs and analyzed by HPLC ${ }^{32}$. We also attempted this quantitative removal as well as measuring the unadsorbed $c$-PEG in the supernatant ${ }^{38}$. However, these methods need to isolate PEGylated AuNPs from the excess PEG molecules, but this was not possible for $c$-PEGphysiosorbed AuNPs. Thus, repeated centrifugation or ultrafiltration removed $c$-PEG from AuNPs, suggesting that the present physisorption system is dynamic in contrast to the gold-sulfur chemisorption, despite providing the good dispersion stability. In addition, the estimated numbers of PEG molecules and Au atoms present per one AuNP are listed in Supplementary Table 3. For example, in the case of AuNPs 15 and PEG with $M_{\mathrm{n}}$ of $3000 \mathrm{Da}$ at a concentration of $0.25 \mathrm{wt} \%$, it is estimated that an average of $10.5 \times$ $10^{4} \mathrm{Au}$ atoms form a nanoparticle ${ }^{39}$, and $38.2 \times 10^{4}$ PEG molecules exist per one nanoparticle.

FT-IR. In order to determine the interaction between the surface of AuNPs and PEG, FT-IR spectroscopy was performed on AuNPs $_{15} / \mathrm{No}$ PEG, AuNPs $15 / \mathrm{MeO}-\mathrm{PEG}_{3 \mathrm{k}}-\mathrm{OMe}$, and AuNPs $\mathrm{s}_{15} / \mathrm{c}$ $\mathrm{PEG}_{3 \mathrm{k}}$. The samples were prepared by moderately removing excess PEG and sodium citrate by ultrafiltration followed by lyophilization. Lyophilization was necessary because water has strong absorptions in the intended wavenumber range. Although FT-IR spectroscopy of the lyophilized samples may not fully reflect the aqueous dispersion state of AuNPs/PEG, the interactions existing between AuNPs and PEG were expected to be investigated. The spectra showed noticeable difference in absorption wavenumbers between $\mathrm{AuNPs}_{15} / \mathrm{MeO}-\mathrm{PEG}_{3 \mathrm{k}}-\mathrm{OMe}$ and AuNPs $_{15} / c-$ PEG $_{3 \mathrm{k}}$ (Supplementary Fig. 14 and Supplementary Table 4). For example, the $\mathrm{CH}_{2}$ rocking and twisting of PEG were higher in wavenumber for $\mathrm{AuNPs}_{15} / c-\mathrm{PEG}_{3 \mathrm{k}}\left(961 \mathrm{~cm}^{-1}\right)$ than AuNPs $_{15} / \mathrm{MeO}-\mathrm{PEG}_{3 \mathrm{k}}-\mathrm{OMe}\left(957 \mathrm{~cm}^{-1}\right)^{40}$. Moreover, the $\mathrm{C}-\mathrm{O}$ and $\mathrm{C}-\mathrm{C}$ stretching of PEG was also higher for $\mathrm{AuNPs}_{15} / \mathrm{c}$ -
PEG $_{3 \mathrm{k}}\left(1100 \mathrm{~cm}^{-1}\right)$ than AuNPs $_{15} / \mathrm{MeO}-\mathrm{PEG}_{3 \mathrm{k}}-\mathrm{OMe}(1094$ $\mathrm{cm}^{-1}$ ), where the $\mathrm{C}-\mathrm{O}$ bonds likely interacted to $\mathrm{Na}^{+}$of sodium citrate. AuNPs 15 MeO-PEG $3 \mathrm{k}-\mathrm{OMe}$ exhibited an extra peak at $1455 \mathrm{~cm}^{-1}$ that can also be found in $\mathrm{MeO}-\mathrm{PEG}_{3 \mathrm{k}}-\mathrm{OMe}$ without AuNPs. Thus, this peak likely arose from the effect of the chain end. The asymmetric stretching of $\mathrm{COO}^{-}$of sodium citrate appeared at $1575 \mathrm{~cm}^{-1}$ for $A_{u N P s_{15}} / \mathrm{No} P E G, 1578 \mathrm{~cm}^{-1}$ for AuNPs $_{15} / \mathrm{MeO}-\mathrm{PEG}_{3 \mathrm{k}}-\mathrm{OMe}$, and $1581 \mathrm{~cm}^{-1}$ for $\mathrm{AuNPs}_{15} / \mathrm{c}^{-}$ $\mathrm{PEG}_{3 \mathrm{k}}$. This suggests that $\mathrm{MeO}-\mathrm{PEG}_{3 \mathrm{k}}-\mathrm{OMe}$ interacts with $\mathrm{Na}^{+}$ to cause the change in the $\mathrm{COO}^{-}$stretching wavenumber, and moreover, $c-\mathrm{PEG}_{3 \mathrm{k}}$ results in a stronger interaction. In addition, the peak at $1648-1649 \mathrm{~cm}^{-1}$, not much different in all the samples, was from the asymmetric stretching of $\mathrm{COO}^{-}$of Aucoordinated citrate $^{41}$.

Animal experiments. Applications of nano-sized particles have been extensively developed for bio-medical area, and, especially, AuNPs are widely utilized into biosensing, diagnosis, and in vivo drug delivery ${ }^{42-46}$. Thus, further research into the plasma clearance and tumor accumulation by using tumor bearing mouse would clarify the potential usability of AuNPs/c-PEG in vivo. As seen in Fig. 5e. AuNPs $5 / c-\mathrm{PEG}_{3 \mathrm{k}}$ exhibited slow blood clearance (43.8\% dose/plasma at $10 \mathrm{~min}$, and $18.8 \%$ dose/plasma at $60 \mathrm{~min}$ ), while no stable circulations were observed for $\mathrm{AuNP}_{5} / \mathrm{No}$ PEG and $\mathrm{AuNP}_{5} / \mathrm{MeO}-\mathrm{PEG}_{3 \mathrm{k}}-\mathrm{OMe}$, indicating the topologydependent utility of surface-modification through $c$-PEG. Tumor accumulation also represented the advantage of $\mathrm{AuNP}_{5} / c-\mathrm{PEG}_{3 \mathrm{k}}$ (Fig. 5f). However, on the basis of the previous reports ${ }^{47-49}$, the absolute amount of $\mathrm{AuNPs}_{5} / c-\mathrm{PEG}_{3 \mathrm{k}}$ accumulated into tumor was relatively low values. In fact, $\mathrm{AuNP}_{5} / c-\mathrm{PEG}_{3 \mathrm{k}}$ in this study is assumed to be accumulated by the enhanced permeability and retention (EPR) effect ${ }^{50,51}$, and the relationship between particle size and time course are fundamentally important to obtain EPRdriven tumor accumulation, especially vs hypervascular tumors, i.e., murine colon adenocarcinoma $(\mathrm{C} 26)^{47,52}$. Therefore, the increments in tumor accumulation of nano-sized particle through EPR effect might require additional fine tuning of AuNPs, e.g., particle size, and such additional modification is ongoing in our group. Overall, these results highlight the importance and usability of $c$-PEG as a stabilizer for metal nanoparticle, and our in vivo experiments exhibit the potential effectiveness of AuNPs/c-PEG, prepared through simple physisorption of $c$-PEG against AuNPs, for bio-medical applications.

\section{Discussion}

Concerning the cause of the strong affinity of $c$-PEG to the surface of AuNPs, the less entropic penalty upon adsorption is expected to be the major factor. In other words, the number of conformations that unadsorbed $c$-PEG can take is less than that of the unadsorbed linear PEG (HO-PEG-OH and MeO-PEG $-\mathrm{OMe}$ ) due to their topology. Thus, the entropic penalty upon adsorption onto the surface of AuNPs is smaller for c-PEG, where the adsorption is an entropically unfavorable and enthalpically favorable process. Since $\mathrm{HO}-\mathrm{PEG}-\mathrm{OH}, \mathrm{MeO}-\mathrm{PEG}-\mathrm{OMe}$, and $c$-PEG are consisted of the same PEG repeating units, their enthalpic energy released upon adsorption should be essentially identical, leading to that the adsorption of $c$-PEG is more favorable than $\mathrm{HO}-\mathrm{PEG}-\mathrm{OH}$ and $\mathrm{MeO}-\mathrm{PEG}-\mathrm{OMe}$ in terms of the free energy to form the thicker PEG layer for the enhanced dispersion stabilization.

The stronger affinity of cyclic polymers was also observed against silica nanoparticles ${ }^{38,53}$. Moreover, the stronger adsorption of cyclic polymers onto a surface have been suggested by theoretical and computational studies ${ }^{54-57}$. Cosgrove and coworkers conducted a detailed study on the difference between the 
surface adsorption of cyclic and linear polymers from solutions by the extended lattice theory (Scheutjens-Fleer (SF) theory) ${ }^{58}$. When the surface adsorption energy parameter $\left(\chi_{\mathrm{s}}\right)$ is small, a larger amount of the cyclic polymers is adsorbed than the linear analogs. The difference in the adsorption efficiency between linear and cyclic polymers becomes small with increasing $\chi_{\mathrm{s}}$. This result indicates that the difference between the linear and cyclic chains is negligible when the adsorption is strongly controlled by enthalpy, while the cyclic chain is advantageous when the adsorption enthalpy and entropy are comparable.

In summary, we showed that the drastic enhancement in the dispersion stability of AuNPs by physisorption of $c$-PEG. This methodology allows for AuNPs dispersions to be frozen, lyophilized, heated, and exposed to physiological conditions with even better stability than the most commonly used chemisorption of HS-PEG-OMe. Moreover, the AuNPs/c-PEG system was applied for an animal experiment, finding the advantages of $\mathrm{AuNPs}_{5} / \mathrm{c}-\mathrm{PEG}_{3 \mathrm{k}}$ in blood circulation in contrast to AuNPs $5 / \mathrm{No}$ PEG and $\mathrm{AuNP}_{5} / \mathrm{MeO}-\mathrm{PEG}_{3 \mathrm{k}}-\mathrm{OMe}$. The combination of the dispersion stability against high temperature and physiological conditions, coupled with the accumulation in tumor, would be most suitable to future applications toward photothermal therapy using gold nanoparticles and nanorods. Furthermore, cyclization and physisorption require no chemical modification on the repeating units of the polymer chain, which is excellent match for the biocompatibility of PEG. Likewise, the physisorption would allow for expedient postfunctionalization through chemisorption.

\begin{abstract}
Methods
Materials. Gold nanoparticles (AuNPs) with a diameter of 5, 10, 15, 20, 30, 40, 50, $60,70,80$, and $100 \mathrm{~nm}(0.05 \mathrm{mg} / \mathrm{mL}$ in aqueous $2 \mathrm{mM}$ sodium citrate, nanoComposix), 4-toluenesulfonyl chloride ( $\mathrm{TsCl}$ ) ( $>98.0 \%$, Junsei Chemical Co., Ltd.), sodium chloride $(\mathrm{NaCl})(>99.0 \%$, Kanto Chemical Co., Inc.), potassium hydroxide (KOH) $(>85.5 \%$, Kanto Chemical Co., Inc.), iodomethane ( $>99.5 \%$, Kanto Chemical Co., Inc.), magnesium sulfate $\left(\mathrm{MgSO}_{4}\right)(>98.0 \%$, Kanto Chemical Co., Inc.), $n$-heptane (>99.0\%, Kanto Chemical Co., Inc.), chlorobenzene (>99.0\%, Nacalai Tesque, Inc.), 18-crown 6-ether (Tokyo Chemical Industry Co., Ltd.), and dithiolated poly(ethylene glycol) (HS- $\mathrm{PEG}_{2 \mathrm{k}}-\mathrm{SH}$ ) (Funakoshi Co., Ltd.) were used as received. Tetrahydrofuran (THF), dehydrated stabilizer free ( $>99.5 \%$, Kanto Chemical Co., Inc.), dichloromethane $\left(\mathrm{CH}_{2} \mathrm{Cl}_{2}\right)(>99.0 \%$, Kanto Chemical Co., Inc.), and chloroform $\left(\mathrm{CHCl}_{3}\right)(>99.0 \%$, Kanto Chemical Co., Inc.) were purified by a solvent purification system (MBRAUN MB-SPS-Compact). Poly(ethylene glycol) 950-1050 (HO-PEG ${ }_{1 k}-\mathrm{OH}$ ) (Sigma-Aldrich), poly(ethylene glycol) 2,000 ( $\mathrm{HO}-\mathrm{PEG}_{3 \mathrm{k}}-\mathrm{OH}$ ) (Sigma-Aldrich), poly(ethylene glycol) 4,000 ( $\left.\mathrm{HO}-\mathrm{PEG}_{5 \mathrm{k}}-\mathrm{OH}\right)$ (Kanto Chemical Co., Inc.), poly(ethylene glycol) 6,000 (HO-PEG ${ }_{10 \mathrm{k}}-\mathrm{OH}$ ) (Kanto Chemical Co., Inc.) were purified by passing through a silica gel column using $\mathrm{CHCl}_{3} / \mathrm{MeOH}(90 / 10, \mathrm{v} / \mathrm{v})$ as an eluent. Thiolated poly(ethylene glycol) (HS-PEG ${ }_{3 \mathrm{k}}-\mathrm{OMe}$ ) (Funakoshi Co., Ltd.) was purified by recycling preparative SEC. The molecular weights of PEG in the catalogs deviated from our measurement, and the measurement values are used in this paper.
\end{abstract}

NMR. ${ }^{1} \mathrm{H}(400 \mathrm{MHz})$ and ${ }^{13} \mathrm{C}$ NMR $(100 \mathrm{MHz})$ were measured in $\mathrm{CDCl}_{3}$ or $\mathrm{D}_{2} \mathrm{O}$ using a JEOL JNM-ESC400 instrument at ambient temperature.

SEC. Size exclusion chromatography (SEC) was performed at $40^{\circ} \mathrm{C}$ with THF (flow rate, $1.0 \mathrm{~mL} / \mathrm{min}$ ) using a Shodex GPC-101 gel permeation chromatography system (Shodex DU-2130 dual pump, Shodex RI-71 reflective index detector, and Shodex ERC-3125SN degasser) equipped with a Shodex KF-G guard column $(4.6 \mathrm{~mm} \times 10$ $\mathrm{mm}$; pore size, $8 \mu \mathrm{m})$ and two Shodex KF- $804 \mathrm{~L}$ columns $(8 \mathrm{~mm} \times 300 \mathrm{~mm})$ in series. Polystyrene standard samples were used for calibration.

Recycling preparative SEC. A Japan Analytical Industry LC-908 recycling preparative HPLC system (Hitachi L-7110 pump and JAI RI detector RI-5) was used. JAIGEL-2 $\mathrm{H}$ and $3 \mathrm{H}$ columns and a pre-column were connected in series. $\mathrm{CHCl}_{3}$ was used as the solvent, and the flow rate was set at $3.5 \mathrm{~mL} / \mathrm{min}$.

MALDI-TOF MS. Matrix-assisted laser desorption/ionization time-of-flight mass spectrometry (MALDI-TOF MS) was carried out using an ABSCIEX TOF/TOF 5800 mass spectrometer at the Open Facility, Hokkaido University. A PEG sample $(1.5 \mathrm{mg} / \mathrm{mL}, 10 \mu \mathrm{L})$ was mixed with a matrix (anthralin, $40 \mathrm{mg} / \mathrm{mL}, 25 \mu \mathrm{L}$ ) and ionization regent (silver trifluroroacetate, $40 \mathrm{mg} / \mathrm{mL}, 10 \mu \mathrm{L}$ ), and $0.4 \mu \mathrm{L}$ of the mixture was drop cast on an Opti-TOF 384 -Well Insert $(123 \times 81 \mathrm{~mm})$ plate.
UV-Vis Spectroscopy. Absorption spectra were measured on a JASCO Ubset V670 spectrophotometer at $25^{\circ} \mathrm{C}$ in deionized water using a micro quartz cell (M25UV-2, GL Science Inc. Japan).

Synthesis of $\boldsymbol{c}$-PEG. HO-PEG $\mathrm{Pk}_{1 \mathrm{k}}-\mathrm{OH}, \mathrm{HO}-\mathrm{PEG}_{3 \mathrm{k}}-\mathrm{OH}, \mathrm{HO}-\mathrm{PEG}_{5 \mathrm{k}}-\mathrm{OH}$, and $\mathrm{HO}-\mathrm{PEG}_{10 \mathrm{k}}-\mathrm{OH}$ were cyclized according to a previous report by Cooke et al. ${ }^{26}$. Typically, $\mathrm{HO}-\mathrm{PEG}_{3 \mathrm{k}} \mathrm{-OH}(5.0 \mathrm{~g}, 2.5 \mathrm{mmol})$ and $\mathrm{TsCl}(0.63 \mathrm{~g}, 3.3 \mathrm{mmol})$ were dissolved in a dry THF $(100 \mathrm{~mL})$ by using a $300 \mathrm{~mL}$ three-neck flask and added dropwise to a stirring suspension of $\mathrm{KOH}(3.3 \mathrm{~g})$ in THF $/ n$-heptane $(75 / 25,100 \mathrm{~mL})$ through a syringe pump at $40^{\circ} \mathrm{C}$ under Ar. The addition was conducted over $144 \mathrm{~h}$ at a rate of $0.7 \mathrm{~mL} / \mathrm{h}$. The reaction mixture was stirred for another $24 \mathrm{~h}$ at $40^{\circ} \mathrm{C}$. The resulting suspension was filtered and concentrated under reduced pressure. The residue was redissolved in $\mathrm{CH}_{2} \mathrm{Cl}_{2}$ and washed with a saturated $\mathrm{NaCl}$ solution three times. The combined organic phase was dried over $\mathrm{MgSO}_{4}$ and concentrated under reduced pressure, and the residue was passed through a silica gel column using $\mathrm{CHCl}_{3} / \mathrm{MeOH}$ $(90 / 10 \mathrm{v} / \mathrm{v})$ as an eluent. The obtained solid was dissolved in $\mathrm{CH}_{2} \mathrm{Cl}_{2}$, and $n$-heptane was added to the solution until becoming cloudy. The mixture was heated to $40^{\circ} \mathrm{C}$ and cooled to $25^{\circ} \mathrm{C}$ gave two separated phases. The $n$-heptane phase was collected and concentrated under reduced pressure. This step was conducted three more times to isolate $c-\mathrm{PEG}_{3 \mathrm{k}}(420 \mathrm{mg}, 8.4 \%)$ as colorless solid.

The expected diameter of $c$-PEG, when the polymer forms an ideal right circular conformation, as well as that of 18 -crown- 6 ether, was determined by the simple geometric calculation (circumference $=\pi \times$ diameter) based on the length of HO-PEG-OH

Synthesis of MeO-PEG-OMe. Dimethylation of HO-PEG-OH was performed using a previously reported procedure ${ }^{26}$. For example, a suspension of $\mathrm{KOH}(6.9 \mathrm{~g})$ in chlorobenzene $(60 \mathrm{~mL})$ in a $300 \mathrm{~mL}$ three-neck flask was added dropwise to a solution of $\mathrm{HO}-\mathrm{PEG}_{3 \mathrm{k}}-\mathrm{OH}(5.00 \mathrm{~g})$ in chlorobenzene $(50 \mathrm{~mL})$, followed by the slow addition of iodomethane $(1.05 \mathrm{~g})$ over 50 min under $\mathrm{N}_{2}$. After the addition was completed, the mixture was stirred at $25^{\circ} \mathrm{C}$ for $24 \mathrm{~h}$. The resulting suspension was diluted with $\mathrm{CH}_{2} \mathrm{Cl}_{2}$ and filtered, and the filtrate was concentrated under reduced pressure. The residue was dissolved in $\mathrm{CH}_{2} \mathrm{Cl}_{2}$ and washed with a saturated $\mathrm{NaCl}$ solution three times, dried over $\mathrm{MgSO}_{4}$, and concentrated under reduced pressure. The residue was dissolved in $\mathrm{CHCl}_{3}$, passed through a silica gel column using $\mathrm{CHCl}_{3} / \mathrm{MeOH}(90 / 10 \mathrm{v} / \mathrm{v})$ as an eluent, and concentrated under reduced pressure to give $\mathrm{MeO}-\mathrm{PEG}_{3 \mathrm{k}}-\mathrm{OMe}(3.26 \mathrm{~g}, 65 \%)$ as white solid.

\section{Preparation of AuNPs/HO-PEG-OH, AuNPs/MeO-PEG-OMe, AuNPs/ HS-PEG-OMe, AuNPs/HS-PEG-SH, and AuNPs/c-PEG. Typically,} HO-PEG $3 \mathrm{k}-\mathrm{OH}(25 \mathrm{mg})$ was added to an $A u \mathrm{NP}_{15}$ dispersion $(1.0 \mathrm{~mL})$ in a $2.0 \mathrm{~mL}$ vial, and PEG was dissolved by vortex mixing for $1 \mathrm{~min}$ to form $\mathrm{AuNP}_{15} /$ $\mathrm{HO}-\mathrm{PEG}_{3 \mathrm{k}}-\mathrm{OH}$ with a PEG concentration of $2.5 \mathrm{wt} \%$. The concentration of PEG was controlled by changing the amount of PEG.

Dispersion stability against freezing. $\mathrm{AuNPs}_{15} / \mathrm{No} \mathrm{PEG}, \mathrm{AuNPs}_{15} /$ HO-PEG ${ }_{3 \mathrm{k}}-\mathrm{OH}, \mathrm{AuNP}_{15} / \mathrm{MeO}-\mathrm{PEG}_{3 \mathrm{k}}-\mathrm{OMe}, \mathrm{AuNP}_{15} / \mathrm{HS}-\mathrm{PEG}_{3 \mathrm{k}}-\mathrm{OMe}$, and $\mathrm{AuNPs}_{15} / \mathrm{c}-\mathrm{PEG}_{3 \mathrm{k}}(1.0 \mathrm{~mL})$ with a PEG concentration of $2.5 \mathrm{wt} \%$ were frozen in a household refrigerator overnight. The frozen samples were melted at ambient temperature.

Dispersion stability against lyophilization. $\mathrm{AuNPs}_{15} / \mathrm{No} \mathrm{PEG}, \mathrm{AuNPs}_{15} /$ HO-PEG ${ }_{3 k}-\mathrm{OH}, \mathrm{AuNPs}_{15} / \mathrm{MeO}-\mathrm{PEG}_{3 \mathrm{k}}-\mathrm{OMe}, \mathrm{AuNPs}_{15} / \mathrm{HS}-\mathrm{PEG}_{3 \mathrm{k}}-\mathrm{OMe}$, and $\mathrm{AuNPs}_{15} / c-\mathrm{PEG}_{3 \mathrm{k}}(1.0 \mathrm{~mL})$ with a PEG concentration of $2.5 \mathrm{wt} \%$ were frozen in liquid nitrogen for $1 \mathrm{~min}$ and lyophilized overnight under reduced pressure. Deionized water $(1.0 \mathrm{~mL})$ was added to the residues for redispersion.

Dispersion stability against heating. AuNPs $s_{15} / \mathrm{No} \mathrm{PEG}, \mathrm{AuNPs}_{15} /$ HO-PEG $3 \mathrm{k}-\mathrm{OH}, \mathrm{AuNP}_{15} / \mathrm{MeO}-\mathrm{PEG}_{3 \mathrm{k}}-\mathrm{OMe}, \mathrm{AuNP}_{15} / \mathrm{HS}-\mathrm{PEG}_{3 \mathrm{k}}-\mathrm{OMe}$, and $\mathrm{AuNPs}_{15} / \mathrm{c}-\mathrm{PEG}_{3 \mathrm{k}}(1.0 \mathrm{~mL})$ with a PEG concentration of $0.25 \mathrm{wt} \%$ were placed in a $15 \mathrm{~mL}$ vial with a lid to enclose air and prevent evaporation of water and heated for $4 \mathrm{~h}$ in a water bath set at $85^{\circ} \mathrm{C}$. Likewise, AuNPs $s_{15} / \mathrm{HS}-\mathrm{PEG}_{3 \mathrm{k}}-\mathrm{OMe}, \mathrm{AuNPs}_{15} /$ HS-PEG ${ }_{2 \mathrm{k}}-\mathrm{SH}$, and $\mathrm{AuNPs}_{15} / \mathrm{c}-\mathrm{PEG}_{3 \mathrm{k}}(1.0 \mathrm{~mL})$ with a PEG concentration of 0.25 wt $\%$ were placed in a $15 \mathrm{~mL}$ vial with a lid and heated for $48 \mathrm{~h}$ in a water bath set at $85^{\circ} \mathrm{C}$. Similarly, the heating test of $\mathrm{AuNPs}_{30} / \mathrm{MeO}-\mathrm{PEG}_{3 \mathrm{k}}-\mathrm{OMe} / \mathrm{c}-\mathrm{PEG}_{3 \mathrm{k}}$ and $\mathrm{AuNP}_{30} / \mathrm{HS}-\mathrm{PEG}_{3 \mathrm{k}}-\mathrm{OMe} / \mathrm{c}-\mathrm{PEG}_{3 \mathrm{k}}$ was performed. Typically, $\mathrm{MeO}-\mathrm{PEG}_{3 \mathrm{k}}-\mathrm{OMe}$ (2.25 mg, $0.225 \mathrm{wt} \%)$ and $c-\mathrm{PEG}_{3 \mathrm{k}}(0.25 \mathrm{mg}, 0.025 \mathrm{wt} \%)$ were dissolved in $\mathrm{AuNPs}_{30}$ dispersion $(1.0 \mathrm{~mL})$. The total PEG concentration was $0.25 \mathrm{wt} \%$. The resulting dispersion was placed in a $15 \mathrm{~mL}$ vial with a lid and heated for $4 \mathrm{~h}$ in a water bath set at $85^{\circ} \mathrm{C}$. Photographs and UV-Vis spectra were recorded at the designated times.

Dispersion stability against a PBS buffer solution. A tenfold-concentrated phosphate-buffered saline (PBS) solution ( $\mathrm{pH} 7.4, \mathrm{NaCl} 1500 \mathrm{mM}, \mathrm{Na}_{2} \mathrm{HPO}_{4}$ $81 \mathrm{mM}, \mathrm{NaH}_{2} \mathrm{PO}_{4} 14.7 \mathrm{mM}$ ) was prepared in advance. Typically, AuNPs $15 / \mathrm{No}$ PEG, AuNPs $15 / \mathrm{HO}-\mathrm{PEG}_{3 \mathrm{k}}-\mathrm{OH}, \mathrm{AuNP}_{15} / \mathrm{MeO}-\mathrm{PEG}_{3 \mathrm{k}}-\mathrm{OMe}, \mathrm{AuNP}_{15} /$ $\mathrm{HS}-\mathrm{PEG}_{3 \mathrm{k}}-\mathrm{OMe}$, or $\mathrm{AuNPs}_{15} / \mathrm{c}-\mathrm{PEG}_{3 \mathrm{k}}(0.54 \mathrm{~mL})$ was placed in a micro quartz cuvette to measure an absorption spectrum. Subsequently, the tenfold-concentrated 
PBS solution $(0.06 \mathrm{~mL})$ was added to the cuvette, and the resulting mixture was 0.6 $\mathrm{mL}$ with $\mathrm{pH} 7.4$ and $150 \mathrm{mM}$ of $\mathrm{NaCl}$ with a PEG concentration of $0.25 \mathrm{wt} \%$. A time-course UV-Vis measurement was performed for $1000 \mathrm{~min}$. For the long-term stability test, $\mathrm{AuNP}_{s_{15}} / \mathrm{c}-\mathrm{PEG}_{3 \mathrm{k}}$ was kept at $37^{\circ} \mathrm{C}$ for $14 \mathrm{~d}$ after the addition of the tenfold-concentrated PBS solution.

Stabilization of AuNPs with various diameters. $c-\mathrm{PEG}_{3 \mathrm{k}}(1.5 \mathrm{mg})$ was added to an AuNPs dispersion $(0.54 \mathrm{~mL}$ ) with a diameter of $5,10,15,20,30,40,50,60,70$, 80 , or $100 \mathrm{~nm}$ in a $2 \mathrm{~mL}$ vial and dissolved by vortex mixing for $1 \mathrm{~min}$. Subsequently, the tenfold-concentrated PBS solution $(0.06 \mathrm{~mL})$ was added to AuNPs $/ c$ PEG, and the resulting mixture was $0.6 \mathrm{~mL}$ with $\mathrm{pH} 7.4$ and $150 \mathrm{mM}$ of $\mathrm{NaCl}$ with a PEG concentration of $0.25 \mathrm{wt} \%$. A time-course UV-Vis measurement was performed for $850 \mathrm{~min}$

PEG concentration-dependent stabilization of AuNPs. The tenfold-concentrated PBS solution $(0.06 \mathrm{~mL})$ was added to $\mathrm{AuNPs}_{5} / \mathrm{HO}-\mathrm{PEG}_{5 \mathrm{k}}-\mathrm{OH}(0.54 \mathrm{~mL})$ or $\mathrm{AuNPs}_{5} / \mathrm{c}^{-\mathrm{PEG}_{5 \mathrm{k}}}(0.54 \mathrm{~mL})$, and the resulting mixture was $0.6 \mathrm{~mL}$ with $\mathrm{pH} 7.4$ and $150 \mathrm{mM}$ of $\mathrm{NaCl}$ with a PEG concentration of $0.25,2.5$, or $10 \mathrm{wt} \%$ for $\mathrm{AuNPs}_{5} /$ HO- $\mathrm{PEG}_{5 \mathrm{k}}-\mathrm{OH}$ or $0.025,0.25$, or $2.5 \mathrm{wt} \%$ for $\mathrm{AuNPs}_{5} / c-\mathrm{PEG}_{5 \mathrm{k}}$. A time-course UV-Vis measurement was performed for $1000 \mathrm{~min}$.

DLS and $\zeta$-potential. Zetasizer Nano ZS (Malvern Panalytical Ltd.) with a high precision micro quartz cuvette (ZEN2112, Hellma Analytics) and Zetasizer nano cells (DTS1060, Malvern Instruments Ltd.) were used to measure the diameter and $\zeta$-potential, respectively. All measurements were performed at $25^{\circ} \mathrm{C}$ with 20 scans at most with a $120 \mathrm{~s}$ equilibration time.

FT-IR. $2.0 \mathrm{~mL}$ of AuNPs ${ }_{15} / \mathrm{No}$ PEG (0.25 wt $\left.\%\right)$, AuNPs $s_{15} / \mathrm{MeO} \mathrm{PEG}_{3 \mathrm{k}}-\mathrm{OMe}(0.25$ $\mathrm{wt} \%)$, or $\mathrm{AuNPs}_{15} / c-\mathrm{PEG}_{3 \mathrm{k}}(0.25 \mathrm{wt} \%)$ was ultrafiltrated at $4,700 \mathrm{~g}$ for $20 \mathrm{~min}$ using an Amicon Ultra $-2 \mathrm{~mL}$ centrifugal filter Ultracel $-30 \mathrm{~K}$ twice. Deionized water was added to a total volume of $2.0 \mathrm{~mL}$, and the dispersion was frozen in liquid nitrogen for $1 \mathrm{~min}$ and lyophilized overnight under reduced pressure. The FT-IR spectrum of the lyophilized sample was measured using a PerkinElmer Frontier MIR spectrometer equipped with a single reflection diamond universal attenuated total reflection (ATR) accessory.

Cell lines and animals. C26 cells (supplied by the National Cancer Center, Tokyo, Japan) were cultured with Dulbecco's Modified Eagle's Medium (high glucose, Sigma-Aldrich, D6429) plus 10\% fetal bovine serum (FBS, Dainippon Sumitomo Pharma Co., Ltd.). BALB/c female mice, 6-weeks (18-21 g) were obtained from Oriental Yeast Co., Ltd. (Tokyo, Japan) and were allowed to acclimatize for 5 days before inoculation of tumors. Animals were kept in a temperature-controlled room on $12 \mathrm{~h} / 12 \mathrm{~h}$ light / dark schedule at $22^{\circ} \mathrm{C}$ with food and water ad libitum. A suspension of C26 cells $\left(1.0 \times 10^{6}\right.$ cells/100 $\mu \mathrm{L}$ in PBS) was subcutaneously implanted into BALB/c female mice. Tumor growth was measured by calipebio $\mathrm{Ar}$ measurement and tumor volumes were calculated by the following equation: $V=$ $\left(a \times b^{2}\right) / 2$, where $a$ refers to the tumor width $(\mathrm{mm})$ and $b$ refers to the tumor length $(\mathrm{mm})$. Fourteen-days post-inoculation, the size tumors were reached to $50 \mathrm{~mm}^{3}$, animals were separated into $n=3$ per group and for treatment with: AuNPs $/ \mathrm{No}_{5}$ $\mathrm{PEG}, \mathrm{AuNP}_{5} / \mathrm{MeO}-\mathrm{PEG}_{3 \mathrm{k}}-\mathrm{OMe}$, and $\mathrm{AuNPs}_{5} / \mathrm{c}-\mathrm{PEG}_{3 \mathrm{k}}$ (dose $=5 \mathrm{mg} / \mathrm{kg}$ on a gold basis). The mice were sacrificed 10 and $60 \mathrm{~min}$ after iv, injection. The tumors were excised, washed with PBS and weighed after removing excess fluid. Blood was collected from the inferior vena cava, heparinized, and centrifuged to obtain the plasma. Acid digestion of all samples was carried out using ca. $5.0 \mathrm{~mL}$ of $30 \%$ $\mathrm{HNO}_{3} / 35 \% \mathrm{HCl}$ mixture. Obtained samples were dissolved in 3 vol\% $\mathrm{HNO}_{3}$ aq. $(10 \mathrm{~mL})$ and were filtered by PTFE membrane. Gold concentration was measured by inductivity coupled plasma optical emission spectrometer with yttrium as internal standard. All animal experiments were performed in accordance with the Guidelines for the Care and Use of Laboratory Animals as stated by The University of Tokyo, Tokyo Institute of Technology, and Hokkaido University.

Reporting summary. Further information on research design is available in the Nature Research Reporting Summary linked to this article.

\section{Data availability}

The data that support the findings of this study are available from the corresponding author upon reasonable request. Source data are provided with this paper.

Received: 31 March 2020; Accepted: 27 October 2020;

Published online: 30 November 2020

\section{References}

1. Kelly, K. L., Coronado, E., Zhao, L. L. \& Schatz, G. C. The optical properties of metal nanoparticles: the influence of size, shape, and dielectric environment. $J$. Phys. Chem. B 107, 668-677 (2003).
2. Kim, Y. J., Johnson, R. C. \& Hupp, J. T. Gold nanoparticle-based sensing of "spectroscopically silent" heavy metal ions. Nano Lett. 1, 165-167 (2001).

3. Anker, J. N. et al. Biosensing with plasmonic nanosensors. Nat. Mater. 7, 442-453 (2008).

4. Hasobe, T. et al. Photovoltaic cells using composite nanoclusters of porphyrins and fullerenes with gold nanoparticles. J. Am. Chem. Soc. 127, 1216-1228 (2005).

5. Yan, N., Xiao, C. \& Kou, Y. Transition metal nanoparticle catalysis in green solvents. Coord. Chem. Rev. 254, 1179-1218 (2010).

6. Wiley, B., Sun, Y. G. \& Xia, Y. N. Synthesis of silver nanostructures with controlled shapes and properties. Acc. Chem. Res. 40, 1067-1076 (2007).

7. Radziuk, D., Skirtach, A., Sukhorukov, G., Shchukin, D. \& Möhwald, H. Stabilization of silver nanoparticles by polyelectrolytes and poly(ethylene glycol). Macromol. Rapid Commun. 28, 848-855 (2007).

8. Dong, H. C. et al. One-pot synthesis of robust core/shell gold nanoparticles. J. Am. Chem. Soc. 130, 12852-12853 (2008).

9. Zhang, X., Servos, M. R. \& Liu, J. W. Ultrahigh nanoparticle stability against salt, $\mathrm{pH}$, and solvent with retained surface accessibility via depletion stabilization. J. Am. Chem. Soc. 134, 9910-9913 (2012).

10. Kralik, M. Adsorption, chemisorption, and catalysis. Chem. Pap. 68, 1625-1638 (2014).

11. Zhang, G. et al. Influence of anchoring ligands and particle size on the colloidal stability and in vivo biodistribution of polyethylene glycol-coated gold nanoparticles in tumor-xenografted mice. Biomaterials 30, 1928-1936 (2009).

12. Nam, S., Parikh, D. V., Condon, B. D., Zhao, Q. \& Yoshioka-Tarver, M. Importance of poly(ethylene glycol) conformation for the synthesis of silver nanoparticles in aqueous solution. J. Nanopart. Res. 13, 3755-3764 (2011).

13. Boisselier, E. \& Astruc, D. Gold nanoparticles in nanomedicine: preparations, imaging, diagnostics, therapies and toxicity. Chem. Soc. Rev. 38, 1759-1782 (2009).

14. Ling, K., Jiang, H. \& Zhang, Q. A colorimetric method for the molecular weight determination of polyethylene glycol using gold nanoparticles. Nanoscale Res. Lett. 8, 538 (2013).

15. Seo, E. et al. Highly stable Au nanoparticles with double hydrophilic block copolymer templates: correlation between structure and stability. Polym. Chem. 8, 4528-4537 (2017).

16. Jia, Z. \& Monteiro, M. J. Cyclic polymers: methods and strategies. J. Polym. Sci., Part A: Polym. Chem. 50, 2085-2097 (2012).

17. Laurent, B. A. \& Grayson, S. M. Synthetic approaches for the preparation of cyclic polymers. Chem. Soc. Rev. 38, 2202-2213 (2009).

18. Kricheldorf, H. R. \& Schwarz, G. Cyclic polymers by kinetically controlled step-growth polymerization. Macromol. Rapid Commun. 24, 359-381 (2003).

19. Yamamoto, T. \& Tezuka, Y. Cyclic polymers revealing topology effects upon self-assemblies, dynamics and responses. Soft Matter 11, 7458-7468 (2015).

20. Honda, S., Yamamoto, T. \& Tezuka, Y. Topology-directed control on thermal stability: micelles formed from linear and cyclized amphiphilic block copolymers. J. Am. Chem. Soc. 132, 10251-10253 (2010).

21. Honda, S., Yamamoto, T. \& Tezuka, Y. Tuneable enhancement of the salt and thermal stability of polymeric micelles by cyclized amphiphiles. Nat. Commun. 4, 1574 (2013).

22. Baba, E., Yatsunami, T., Tezuka, Y. \& Yamamoto, T. Formation and properties of vesicles from cyclic amphiphilic PS-PEO block copolymers. Langmuir 32, 10344-10349 (2016).

23. Morgese, G. et al. Topological polymer chemistry enters surface science: linear versus cyclic polymer brushes. Angew. Chem. Int. Ed. 55, 15583-15588 (2016).

24. Morgese, G. et al. Next-generation polymer shells for inorganic nanoparticles are highly compact, ultra-dense, and long-lasting cyclic brushes. Angew. Chem. Int. Ed. 56, 4507-4511 (2017).

25. Morgese, G., Cavalli, E., Rosenboom, J.-G., Zenobi-Wong, M. \& Benetti, E. M. Cyclic polymer grafts that lubricate and protect damaged cartilage. Angew. Chem. Int. Ed. 57, 1621-1626 (2018).

26. Cooke, J. et al. Large cyclic poly(oxyethylene)s: chain folding in the crystalline state studied by Raman spectroscopy, X-ray scattering, and differential scanning calorimetry. Macromolecules 31, 3030-3039 (1998).

27. Tang, Q., Wu, Y., Sun, P., Chen, Y. \& Zhang, K. Powerful ring-closure method for preparing varied cyclic polymers. Macromolecules 47, 3775-3781 (2014).

28. Liu, R. et al. Colorimetric sensing of copper(II) based on catalytic etching of gold nanoparticles. Talanta 112, 37-42 (2013)

29. Smith, A. M. et al. Quantitative analysis of thiolated ligand exchange on gold nanoparticles monitored by ${ }^{1} \mathrm{H}$ NMR spectroscopy. Anal. Chem. 87, 2771-2778 (2015)

30. Bain, C. D., Biebuyck, H. A. \& Whitesides, G. M. Comparison of selfassembled monolayers on gold: coadsorption of thiols and disulfides. Langmuir 5, 723-727 (1989).

31. Kang, T. et al. Mussel-inspired anchoring of polymer loops that provide superior surface lubrication and antifouling aroperties. ACS Nano 10, 930-937 (2016). 
32. Du, Y., Jin, J., Liang, H. \& Jiang, W. Structural and physicochemical properties and biocompatibility of linear and looped polymer-capped gold nanoparticles. Langmuir 35, 8316-8324 (2019).

33. Pamies, R. et al. Aggregation behaviour of gold nanoparticles in saline aqueous media. J. Nanopart. Res. 16, 2376 (2014).

34. Rahme, K. et al. PEGylated gold nanoparticles: polymer quantification as a function of PEG lengths and nanoparticle dimensions. RSC Adv. 3, 6085-6094 (2013).

35. Tao, S. L., Popat, K. C., Norman, J. J. \& Desai, T. A. Surface modification of SU-8 for enhanced biofunctionality and nonfouling properties. Langmuir 24, 2631-2636 (2008).

36. Damodaran, V. B., Fee, C. J., Ruckh, T. \& Popat, K. C. Conformational studies of covalently grafted poly(ethylene glycol) on modified solid matrices using Xray photoelectron spectroscopy. Langmuir 26, 7299-7306 (2010).

37. Uz, M., Bulmus, V. \& Altinkaya, S. A. Effect of PEG grafting density and hydrodynamic volume on gold nanoparticle-cell interactions: an investigation on cell cycle, apoptosis, and DNA damage. Langmuir 32, 5997-6009 (2016).

38. Wang, Y., Qin, W. \& Qiu, D. Small-angle neutron scattering study of cyclic poly(ethylene glycol) adsorption on colloidal particles. Langmuir 30, 5170-5175 (2014).

39. Oh, E. et al. Cellular uptake and fate of PEGylated gold nanoparticles is dependent on both cell-penetration peptides and particle size. ACS Nano 5 , 6434-6448 (2011).

40. Vrandečić, N. S., Erceg, M., Jakić, M. \& Klarić, I. Kinetic analysis of thermal degradation of poly(ethylene glycol) and poly(ethylene oxide)s of different molecular weight. Thermochim. Acta 498, 71-80 (2010).

41. Wulandari, P. et al. Characterization of citrates on gold and silver nanoparticles. J. Colloid Interface Sci. 438, 244-248 (2015).

42. Elsabahy, M. \& Wooley, K. L. Design of polymeric nanoparticles for biomedical delivery applications. Chem. Soc. Rev. 41, 2545-2561 (2012).

43. Sutton, D., Nasongkla, N., Blanco, E. \& Gao, J. M. Functionalized micellar systems for cancer targeted drug delivery. Pharm. Res. 24, 1029-1046 (2007).

44. Agasti, S. S. et al. Nanoparticles for detection and diagnosis. Adv. Drug Deliv. Rev. 62, 316-328 (2010).

45. Knop, K., Hoogenboom, R., Fischer, D. \& Schubert, U. S. Poly(ethylene glycol) in drug delivery: pros and cons as well as potential alternatives. Angew. Chem., Int. Ed. 49, 6288-6308 (2010).

46. Otsuka, H., Nagasaki, Y. \& Kataoka, K. PEGylated nanoparticles for biological and pharmaceutical applications. Adv. Drug Deliv. Rev. 55, $403-419$ (2003).

47. Cabral, H. et al. Accumulation of sub- $100 \mathrm{~nm}$ polymeric micelles in poorly permeable tumours depends on size. Nat. Nanotechnol. 6, 815-823 (2011).

48. Bae, Y. et al. Preparation and biological characterization of polymeric micelle drug carriers with intracellular $\mathrm{pH}$-triggered drug release property: Tumor permeability, controlled subcellular drug distribution, and enhanced in vivo antitumor efficacy. Bioconjugate Chem. 16, 122-130 (2005).

49. Cabral, H., Nishiyama, N., Okazaki, S., Koyama, H. \& Kataoka, K. Preparation and biological properties of dichloro(1,2-diaminocyclohexane)platinum(II) (DACHPt)-loaded polymeric micelles. J. Control. Release 101, 223-232 (2005).

50. Matsumura, Y. \& Maeda, H. A new concept for macromolecular therapeutics in cancer chemotherapy: mechanism of tumoritropic accumulation of proteins and the antitumor agent smancs. Cancer Res. 46, 6387-6392 (1986).

51. Maeda, H., Tsukigawa, K. \& Fang, J. A retrospective 30 years after discovery of the enhanced permeability and retention effect of solid tumors: nextgeneration chemotherapeutics and photodynamic therapy-problems, solutions, and prospects. Microcirculation 23, 173-182 (2016).

52. Miura, Y. et al. Polymeric micelle platform for multimodal tomographic imaging to detect scirrhous gastric cancer. ACS Biomater. Sci. Eng. 1, 1067-1076 (2015).

53. Patel, A., Cosgrove, T. \& Semlyen, J. A. Studies of cyclic and linear poly (dimethylsiloxanes): 30. adsorption studies on silica in solution. Polymer 32, 1313-1317 (1991).

54. Stratouras, G. K. \& Kosmas, M. K. On the density profile of ring chains interacting with a surface. Macromolecules 24, 6754-6758 (1991).
55. Stratouras, G. \& Kosmas, M. Are ring polymers adsorbed on a surface more than linear polymers? Macromolecules 25, 3307-3308 (1992).

56. Zhang, L., Xia, A. \& Xu, Y. Statics and dynamics of adsorbed ring polymer chains. Eur. Polym. J. 36, 847-850 (2000).

57. Sikorski, A. Computer simulation of adsorbed polymer chains with a different molecular architecture. Macromol. Theory Simul. 10, 38-45 (2001)

58. van Lent, B., Scheutjens, J. \& Cosgrove, T. Self-consistent field-theory for the adsorption of ring polymers from solution. Macromolecules 20, 366-370 (1987).

\section{Acknowledgements}

This work was supported by JSPS Program for Leading Graduate Schools (Hokkaido University "Ambitious Leader's Program") (Y.W.), Grant-in-Aid for JSPS Fellows (J.E.Q.Q.), Grants-in-Aid for Scientific Research (B) (16H05422, Y.M.), Grant-in-Aid for Young Scientists (A) (17H04878, T.Y.), Scientific Research on Innovative Areas "Discrete Geometric Analysis for Materials Design" (18H04470 T.Y.) and the Asahi Glass Foundation (T.Y.). We thank the Open Facility, Global Facility Center, Creative Research Institution, Hokkaido University for allowing us to conduct the analysis of PEG using an ABSCIEX TOF/TOF 5800 mass spectrometer.

\section{Author contributions}

Y.W., J.E.Q.Q., and T.O. performed the synthesis, dispersion stability experiments, and FT-IR measurement. M.M. and M.T. performed the DLS and $\zeta$-potential measurements. T.I., K.T., and T.S. contributed to performing the synthesis and analysis of the data. S.S. performed the analysis of the interactions between AuNPs and PEG. Y.M. performed the animal experiment. T.Y. designed the experiments and supervised the project. All the authors discussed the results and contributed to the paper.

\section{Competing interests}

The authors declare no competing interests.

\section{Additional information}

Supplementary information is available for this paper at https://doi.org/10.1038/s41467020-19947-8.

Correspondence and requests for materials should be addressed to T.Y.

Peer review information Nature Communications thanks Wei Jiang and the other, anonymous, reviewers for their contribution to the peer review of this work.

Reprints and permission information is available at http://www.nature.com/reprints

Publisher's note Springer Nature remains neutral with regard to jurisdictional claims in published maps and institutional affiliations.

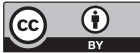

Open Access This article is licensed under a Creative Commons Attribution 4.0 International License, which permits use, sharing, adaptation, distribution and reproduction in any medium or format, as long as you give appropriate credit to the original author(s) and the source, provide a link to the Creative Commons license, and indicate if changes were made. The images or other third party material in this article are included in the article's Creative Commons license, unless indicated otherwise in a credit line to the material. If material is not included in the article's Creative Commons license and your intended use is not permitted by statutory regulation or exceeds the permitted use, you will need to obtain permission directly from the copyright holder. To view a copy of this license, visit http://creativecommons.org/ licenses/by/4.0/.

(c) The Author(s) 2020 